\title{
Mechanical and microstructural characterization of titanium gr. 5 parts produced by different manufacturing routes
}

Davide Campanella ( $\sim$ davide.campanella@unipa.it)

University of Palermo

Gianluca Buffa

Andrea El Hassanin

Antonino Squillace

Francesco Gagliardi

Luigino Filice

Livan Fratini

\section{Research Article}

Keywords: Ti Grade5, hot forging, additive manufacturing, machining, geometrical accuracy

Posted Date: February 21st, 2022

DOI: https://doi.org/10.21203/rs.3.rs-1366133/v1

License: (9) This work is licensed under a Creative Commons Attribution 4.0 International License. Read Full License 


\title{
Mechanical and microstructural characterization of titanium gr.5 parts produced by different manufacturing routes
}

\author{
Davide Campanella ${ }^{\mathrm{a},}$, , Gianluca Buffa ${ }^{\mathrm{a}}$, Andrea El Hassanin ${ }^{\mathrm{b}}$, Antonino Squillace ${ }^{\mathrm{b}}$, Francesco \\ Gagliardic ${ }^{\mathrm{c}}$, Luigino Filice ${ }^{\mathrm{c}}$ and Livan Fratini ${ }^{\mathrm{a}}$,
}

\begin{abstract}
a Department of Engineering, University of Palermo, viale delle Scienze, Palermo, 90128, Italy
' Department of Chemical, Materials and Industrial Production Engineering, University of Naples "Federico II", P.le Tecchio 80, Naples, 80125, Italy

${ }^{\mathrm{c}}$ Department of Mechanical, Energy and Management Engineering, University of Calabria, Rende, 87036, Italy
\end{abstract}

"Corresponding author.

E-mail address: davide.campanella@unipa.it

\begin{abstract}
In recent years, the aircraft industry has shifted its preference for metal parts to titanium and its alloys, such as the high-strength Titanium Grade5 alloy. Because of Titanium Grade 5 limited formability at ambient temperature, forming operations on this material require high temperatures. In these conditions, a peculiar microstructure evolves as a result of the heating and deformation cycles, which has a significant impact on formability and product quality. On the other hand, additive manufacturing technologies, as selective laser melting and electron beam melting, are increasingly being used and are replacing more traditional approaches such as machining and forging. Fundamental parts characteristics as mechanical and microstructural properties, geometric accuracy and surface quality strongly depend on the selection of the manufacturing method. The authors of this paper seek to identify the strengths and limitations imposed by the intrinsic characteristics of different manufacturing alternatives for the production of parts of aeronautical significance, providing guidelines for the choice of the most appropriate manufacturing route for given application and part design.
\end{abstract}

Keywords: Ti Grade5, hot forging, additive manufacturing, machining, geometrical accuracy

\section{Introduction}

Based on the phase composition, titanium (Ti) alloys are typically categorized into three primary groups, i.e., $\alpha, \alpha+\beta$ and $\beta$. $\alpha$ stabilizers (such as Al), $\beta$ stabilizers (such as Mo and $\mathrm{Mn}$ ), and neutral elements (such as $\mathrm{Sn}$ and $\mathrm{Zr}$ ) are the most common alloying elements for $\mathrm{Ti}$ [1]. Different crystal structures have a vital influence in determining Ti alloy characteristics. Traditional processes such as casting, forging, and powder metallurgy are commonly used to manufacture Ti-based components. Titanium alloys have a high specific strength and corrosion resistance, and, for these reasons they are utilized successfully in a variety of industries, including aircraft, power and chemical machine building, sporting equipment, and medical device manufacturing [2].

As far as the aerospace sector is regarded, functional performance, lead time reduction, light weighting, part complexity, cost management, and sustainability are all interacting technical and economic objectives to be considered. Each of these goals has a strong relationship with the others, and the limitations of a given production approach must be carefully examined when choosing an ideal design solution [3]. Unfortunately, the COVID-19 pandemic has had a 
significant detrimental impact on the aircraft sector, with sales falling from $\$ 342.2$ billion in 2019 to $\$ 298$ billion in 2020 [4]. Air travel limitations, social distancing protocols, and other restrictions put on the commercial aviation industry during the ongoing COVID-19 epidemic were the primary reason of this reduction. Despite these obstacles, the aircraft industry is predicted to generate $\$ 430.87$ billion in revenue by 2025 [4]. This increase is partly due to long-term demand for new commercial aircraft, rising global military spending, high market activity in the space sector, and significant research and development that has continued during the epidemic [4].

Today, most of the titanium components are produced by machining. However, for these processes, difficulties arise due to peculiar properties of titanium alloys [5]:

- High chemical reactivity - During the machining process, titanium tends to weld to the tool, resulting in chipping and premature tool failure.

- Low thermal conductivity - This causes an increase in temperature at the tool-workpiece interface, reducing tool life.

- Low elastic modulus - The elasticity of titanium adds to the manufacturing difficulties. The material's elasticity leads it to spring away from the cutting tool under cutting forces, causing edges to rub together (rather than cut), increasing friction, and boosting the temperature at the cutting area. Additionally, Kirk highlighted that the Titanium chip is exceedingly thin, resulting in an unusually small contact area with the tool (one-third of the contact area of steel at the same feed rate and depth of cut) [6]. Ezugwu et al. [7] attempted to manufacture titanium alloys in an inert argon enriched environment in order to reduce chemical reactions at the tool chip and tool workpiece interfaces when machining titanium alloys at high speeds.

Because of their potential to provide a near net shaped product with a limited machining needed after the process, forging of titanium alloys has got increasing attention from both the industrial and scientific world in the last decade [8]. However, if a defective microstructure occurs during the forging process, it is difficult to modify it by subsequent heat treatment. Furthermore, titanium alloys are extremely sensitive to the forging process, during which the temperature history determines the solid phase transformation, and influences the shape, size, proportion, and distribution of phases [9]. Due to the difficulties in filling dies with the alloy to get the designed geometry, titanium alloys are classified as a difficult-to-forge materials.

Furthermore, titanium alloy forgings of aeronautical components, particularly for rotating elements as engine disks and shafts, must be extremely reliable. As a result, during forging, temperature, strain, and strain rate must be closely monitored to ensure that the material attributes and quality inspection standards are met. In order to understand the many variables playing a role in the process, a few authors focused on an economically driven approach for creating aeronautical interest parts that are as near net shape as possible using hot forging, demonstrating that numerical techniques may be used to envisage process and product features [10]. Hu et al. focused on the characteristics that have a significant impact on the evolution of the microstructure and the quality of forged products. Using two-dimensional FEM analysis, the development of the workpiece's microstructure was investigated during forging [11].

On the other hand, Additive Manufacturing is becoming increasingly popular in a variety of industries, including aerospace and biomedical. After reviewing many of the existing 3D printing processes, Frazier [12] stated that "Additive Production has the ability to change the global parts manufacturing and logistics scene". While additive manufacturing can produce near net shape objects, when strict dimensional tolerances and high surface finish are required, a traditional subtractive manufacturing operation, such as machining, is still necessary for most applications. Shoulder milling is a common machining process for removing the rough surface finish typical of most 3D printed parts, usually characterized by greater surface tolerance and roughness with respect to design requirements as an example, a smooth surface on turbine blades in airplanes is critical for improved fatigue performance and reduced corrosion [13]. 
While various Additive Manufacturing processes are currently accessible, one of the main issues is to control input parameters such as powder size, energy input and feeding methods, as well as to be able to predict the final product quality. For processing titanium and related alloys, direct energy deposition (DED) and powder bed fusion (PBF) can be considered as standard AM processes [14], while novel 3D printing techniques are continually being developed [15]. There are several methods for creating 3D printed metal designs but understanding the resulting material properties is critical for proper implementation. Varying 3D printing methods produce materials with different microstructures and mechanical qualities, affecting their hardness and machinability. Rapid temperature changes during 3D printing create significant changes in the microstructure, which in turn causes variations in the material's hardness [16]. Depending on the application of the manufactured item, different material qualities may be required, and determining which AM method is the best, when combined with the machining finish process, might be difficult. Comparing different AM processes and learning more about how later machining operations may alter material qualities and surface integrity is thus quite important. Nowadays, powder bed fusion process as Selective Lase Melting (SLM) also known Laser Powder Bed Fusion, (L-PBF) and Electron Beam Melting (EBM) also known Electron Powder Bed Fusion, (E-PBF) are the most utilized for industrial applications.

In this paper two case studies, characterized by geometrical features typical of aeronautical application parts, have been identified: one with a simpler geometry and the other with a more sophisticated geometrical structure. The parts were produced, using the Ti6Al4V titanium alloy, following three alternative manufacturing routes:

- Subtractive Manufacturing, (machining process)

- Mass conservation (forging process + machining process)

- Additive manufacturing procedures (Laser Powder Bed Fusion or Electron Powder Bed Fusion)

Based on the technique chosen, the material goes through different thermal, chemical, physical, and mechanical cycles affecting the final microstructure (both in the core and on the piece's surface), which will determine the final components mechanical properties. In order to compare the different approaches, comparative analyses have been carried out focusing on geometrical accuracy, surface characterization and mechanical properties. The authors' aim is to provide a decision-support tool to the academic and industrial communities for identifying the most appropriate approach for given application and geometrical features.

\section{Experimental processes and conditions}

For the experimental campaign, two different case studies were analyzed. Fig. 1 shows the two parts $3 \mathrm{~d}$ sketch and lateral views with dimensions. For the first geometry, an axisymmetric part, characterized by a simple geometry, was taken into account, while for the second part a more complex geometry, due to the presence of thin walls, was considered. 

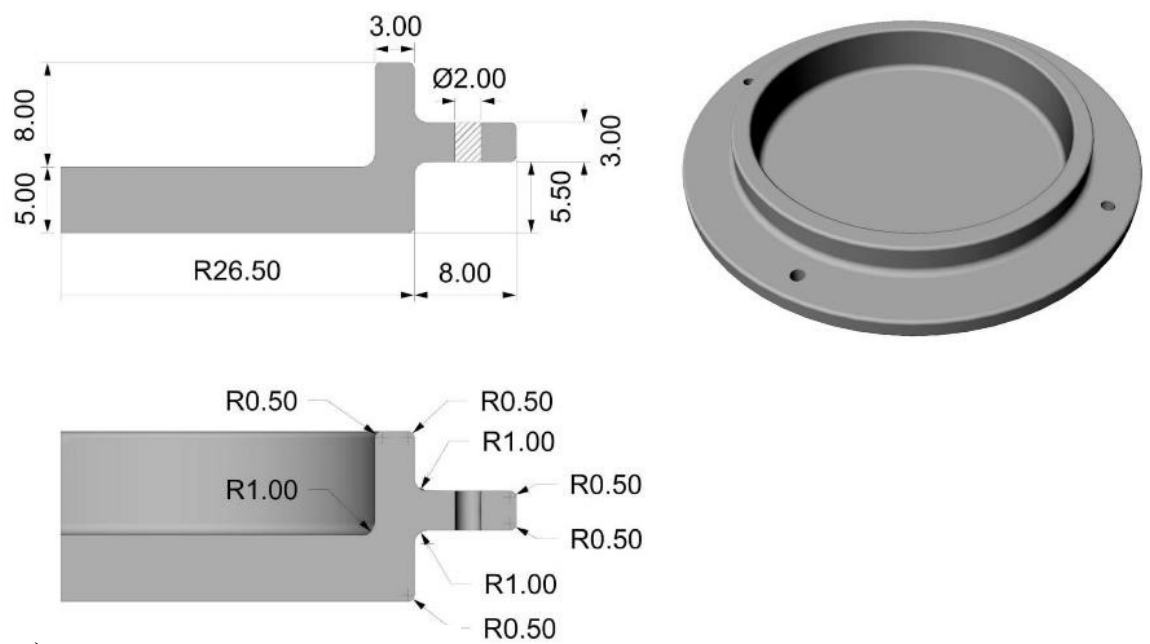

a)

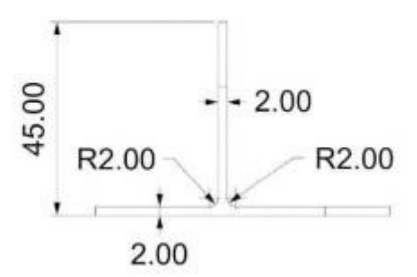

R15.00

FRONT VIEW
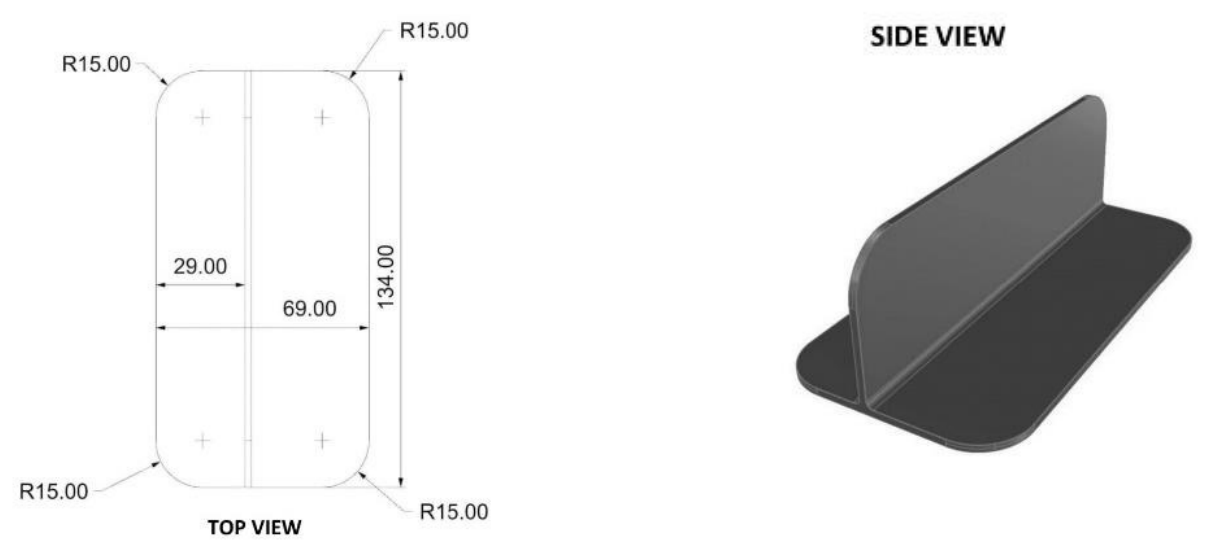

b)

Fig. 1 Sketch parts a) case study 1 and b) case study 2

\subsection{Material used}

The material utilized in the present investigation is the $\alpha-\beta$ titanium alloy Ti6Al4V that accounts for more than $50 \%$ of the whole titanium alloy industrial production and is widely utilized in the aeronautic industry for its high ratio between the strength and mass $[19,20]$.

\subsubsection{Composition and morphology of initial raw bar}

In the case of the forging and machining process, raw bars characterized by different diameters and lengths, as better specified in the following, were used Even at high temperature, this material presents a limited forgeability window [20], which makes it necessary to carefully select the working parameters utilized in its hot forging. 
The microstructure of the as received Ti6Al4V bars, in different directions, is reported in Fig. 2 . The typical microstructure characterized by alpha grains (about $92 \%$ ) in a beta matrix (about $8 \%$ ) is visible.
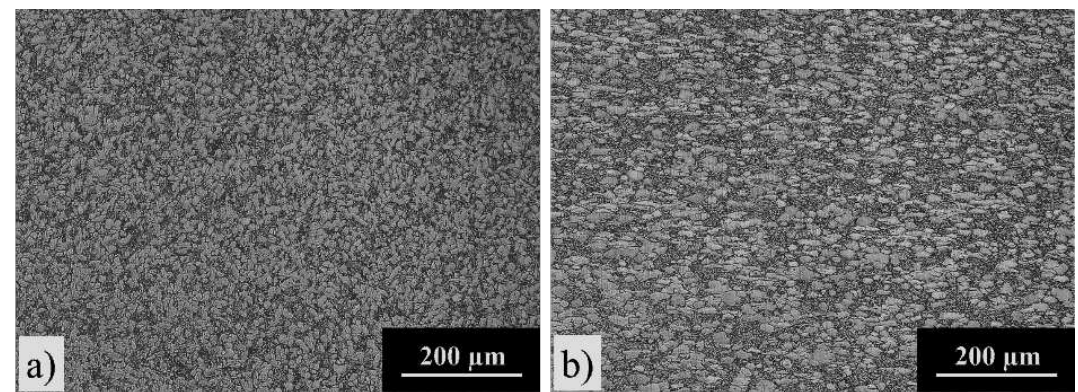

Fig. 2 SEM images of raw bars for a) transversal and b) longitudinal sections

\subsubsection{Composition and morphology of initial powders}

In the case of Additive Manufacturing strategy, the process was started from powder. The Ti6Al4V powder chemical composition is reported in Table 1.

Table 1. Chemical composition of the Ti-6Al-4V powder alloy.

\begin{tabular}{cccc}
\hline & \multicolumn{3}{c}{ Element } \\
\cline { 2 - 4 } Weight $\%$ & Ti & Al & Valance \\
\hline
\end{tabular}

The used Ti6Al4V powders were typical Gaussian powders with particle size ranging between 20 and $60 \mu \mathrm{m}$ for the L-PBF process (Fig. 3a) and with sizes between 45 and $106 \mu \mathrm{m}$ for Electron Powder Bed Fusion process (Fig. 3b).

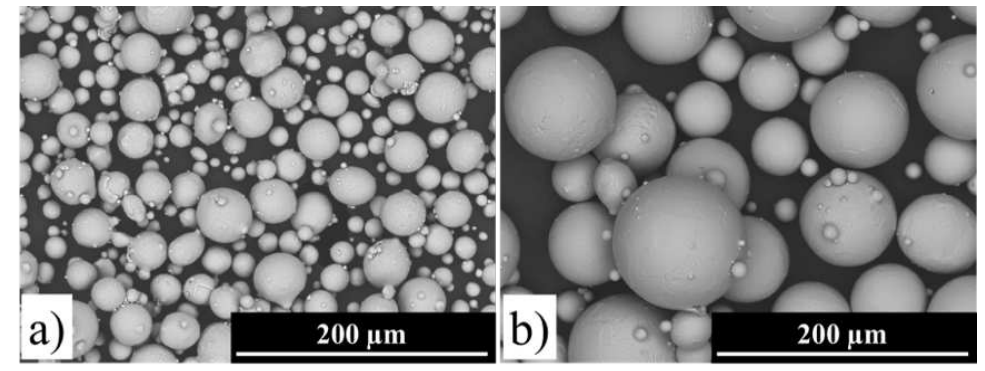

Fig. 3 SEM images of powders for a) L-PBF process and b) E-PBF process

\subsection{Techniques used}

Three different techniques were used for this research as detailed in the following sub sections.

\subsubsection{Forging process}

Two different approaches can be used for the forging of this alloy: (i) the $\alpha-\beta$ forging, which occurs temperatures below the $\beta$-transus temperature (equal to about $995^{\circ} \mathrm{C}$ ) and results in components with a microstructure made of equiaxial primary $\alpha$ in a transformed $\beta$ matrix, having an optimal combination of strength and fatigue properties; (ii) the $\beta$ forging, for which the process is carried out above the $\beta$-transus temperature, resulting in acicular primary $\alpha$ in a transformed $\beta$ matrix, with consequent enhancement of the fracture-related properties. In the 
present study, the second approach, namely forging at temperatures higher the $\beta$-transus, was used.

For the forging process, the tests were carried out on a Mecolpress Series T screw press with maximum load of $5600 \mathrm{kN}$ (Fig. 4a). The billets were $50 \mathrm{~mm}$ in diameter and $20 \mathrm{~mm}$ in length cylinders for the first case study, while for the second case study $130 \mathrm{~mm}$ long cylinders having a diameter of $45 \mathrm{~mm}$ were used.

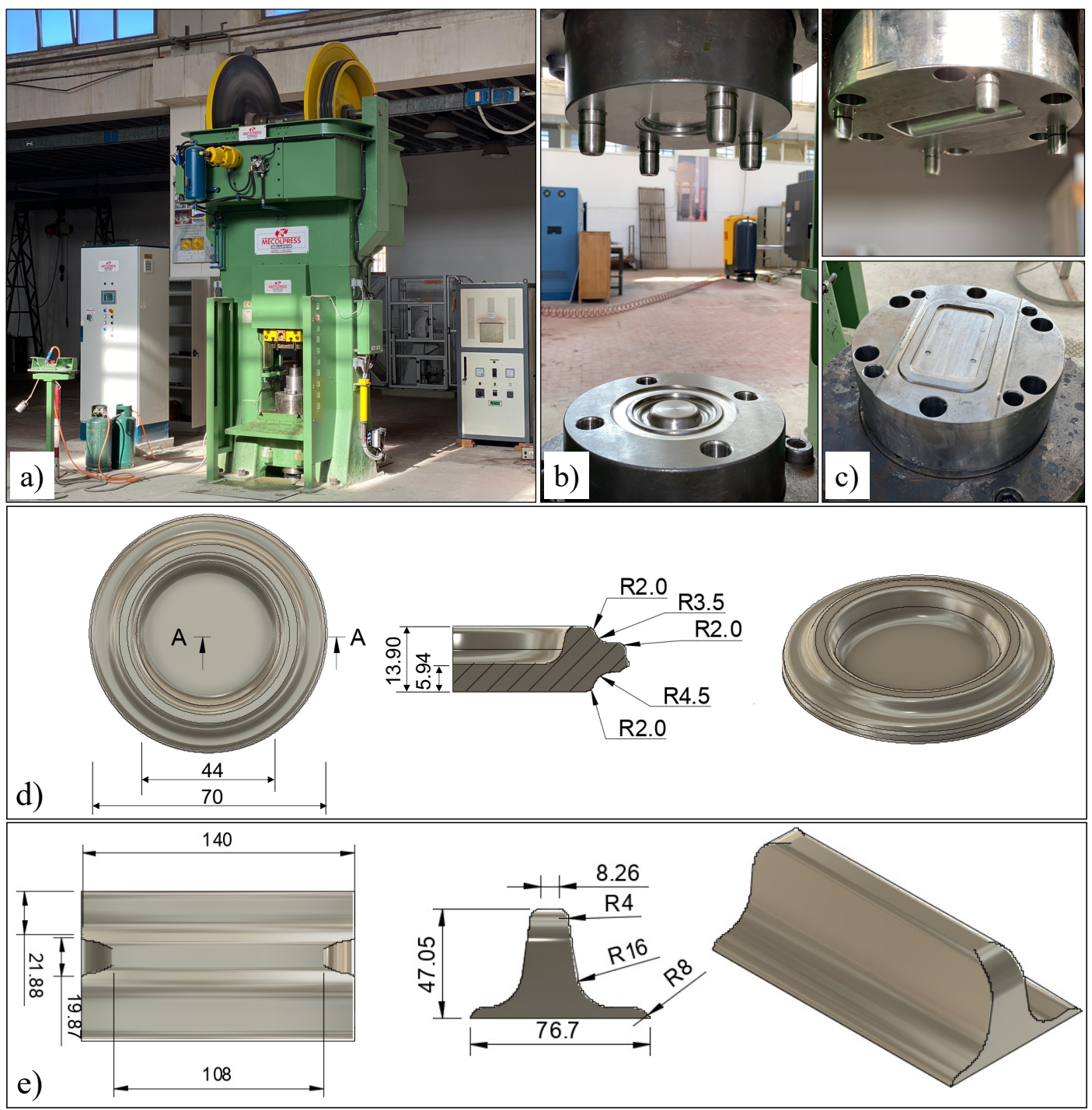

Fig. 4 a) Screw press used for forging: Mecolpress Series T, dies used for b) case study 1 and c) case study 2 and final geometries in millimeters for d) case study 1 and e) case study 2

The dies utilized for the forging tests were made in $\mathrm{H} 13$ steel. Fig. 4b-e shows the dies and the forged part geometry obtained by preliminary FEM simulations in order to reach an acceptable compromise between part geometry, as close as possible to the final part, and forging load.

Both the lower and the upper die were heated through resistance cartridge heaters up to a temperature of about $280^{\circ} \mathrm{C}$. The heating of the billets was carried out by means of an induction furnace (Fig. 5a). On exiting the furnace, the billets were manually positioned on the lower die of the press: the average temperature measured on the billet surface through an infrared thermocamera, just before the forging hit, were approximately equal to $1100{ }^{\circ} \mathrm{C}$ (for the first case study) and equal to $1400{ }^{\circ} \mathrm{C}$ (for the second case study). This difference is due to the need to 
keep the overall forging load within the press limits because of the more complex geometry of the second case study. For the entire experimental process, 45 min were spent on heating while about 12 seconds were required for the billet positioning and the subsequent forging test. The scheme of the experimental set-up is shown in Fig. 5 b.
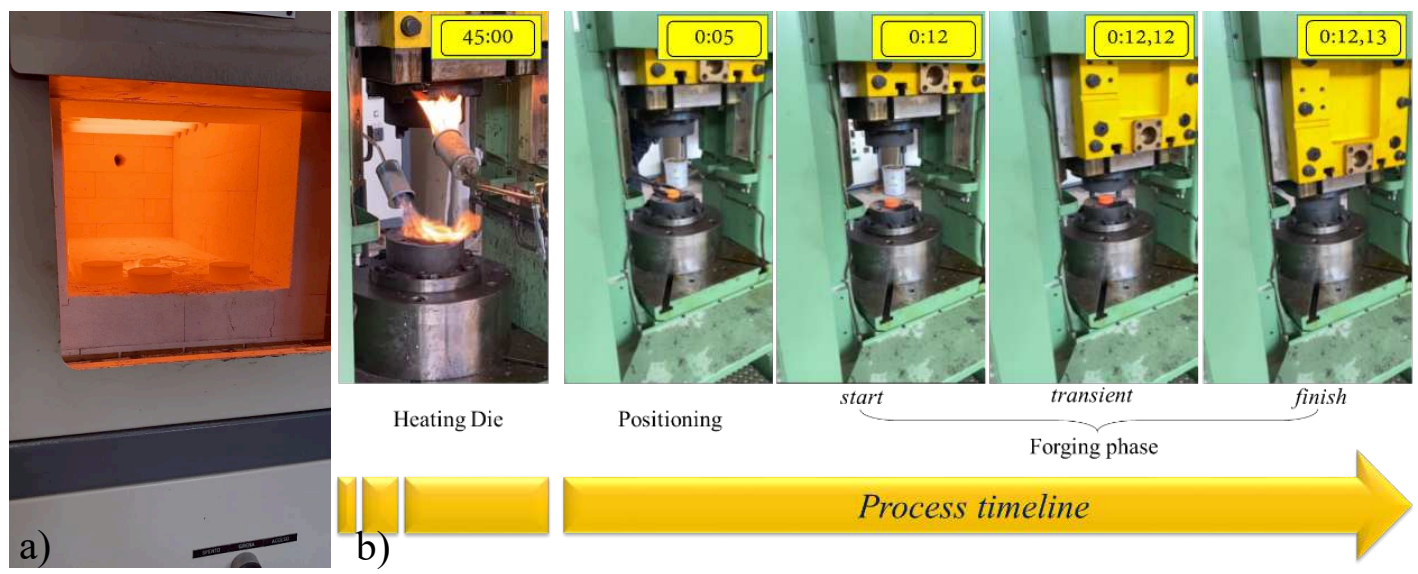

Fig. 5 a) Induction furnace and b) Process timeline before and during the forging test

For the experiments, a water-based concentrate containing synthetic graphite was used as lubricant. The Kinetic Energy required was $14 \mathrm{~kJ}$ for the first case study and $28 \mathrm{~kJ}$ for the second case study.

\subsubsection{Machining process}

The final parts were machined starting from cylindrical billets obtained by casting and from the semi-finished forged parts. The axisymmetric shape (Fig.1a) was produced by turning operations while the T-shape was obtained by milling. The T-shape was characterized by a fillet radius of $2 \mathrm{~mm}$ at the bottom side of the wing (Fig.1b). The experiments were performed on a Mazak Variaxis j-600/5x equipped with S30T Sandvik inserts mounted on a milling cutter with a diameter of $20 \mathrm{~mm}$ and a Mazak Quick Turn Compact 300MY equipped by turning sharp cutters designed for titanium alloys. The inserts are characterized by a specific coating, developed for Titanium alloys, made of a carbide substrate to improve the fatigue and microchipping resistances of the tool sharp edges.

Regarding the clamping of the forged T-shape workpieces, a customized and homemade clamping frame, where the forged elements were inserted and blocked in, was employed (Fig. $6)$.

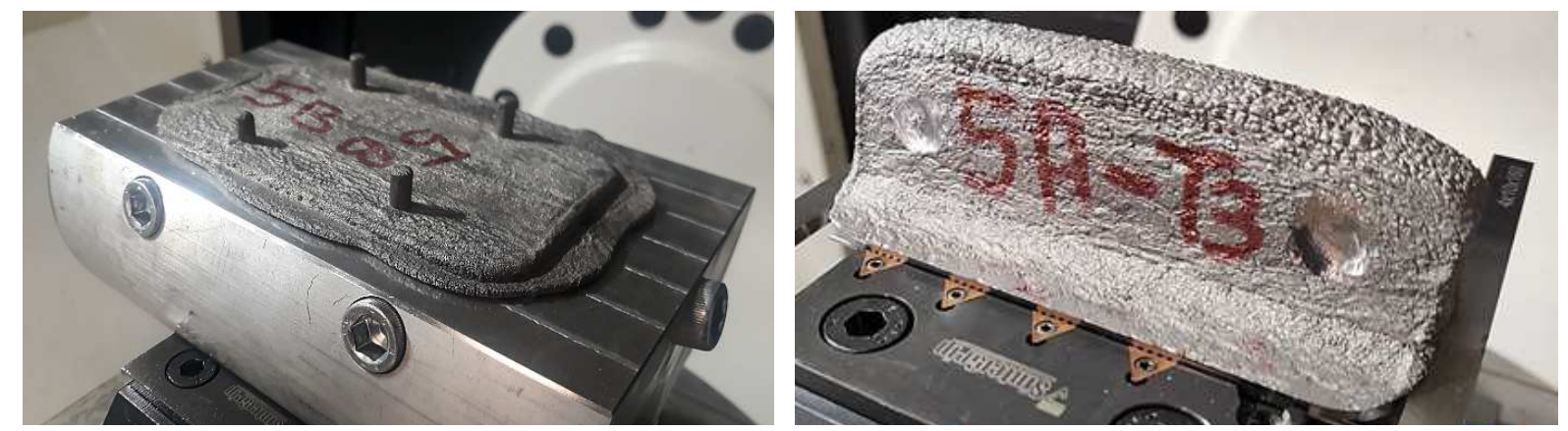

Fig. 6 A forged specimen blocked in a specific clamping frame.

The tool paths for each configuration were generated by a dedicated CAM software. The trajectory was optimized to reduce the processing time by scanning the shape of each forged component to have a clear view of the material to be machined (Fig. 7). 


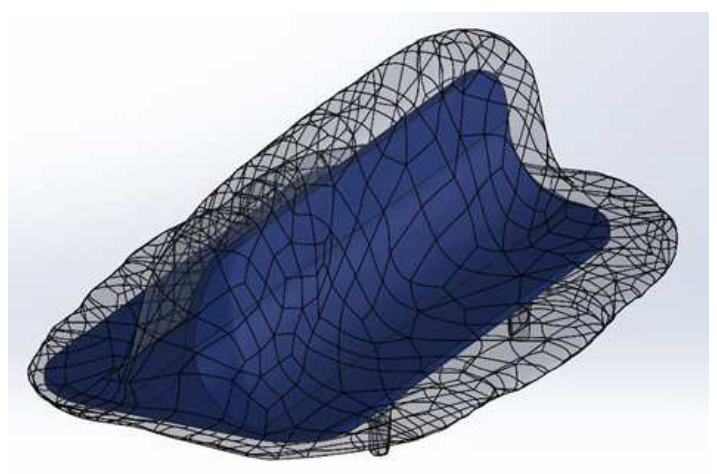

Fig. 7 Scanned shape of a forged part (meshed part) and the component to be machined (blue part).

It is worth noting that this step was not required for the casted billets being characterized by a standard initial workpiece. Finally, for all the configurations, a butyl adhesive sealant was used on the wing side in contact with the frame to reduce possible vibrations owing to the reduced thickness of the part to be milled. Notwithstanding the selected insert, owing to asperities and hardness of the surfaces of the forged parts (Fig. 8), a discordance strategy of the tool path was chosen to avoid dangerous collisions between tool and processed material at the cutter entry preserving the insert life.

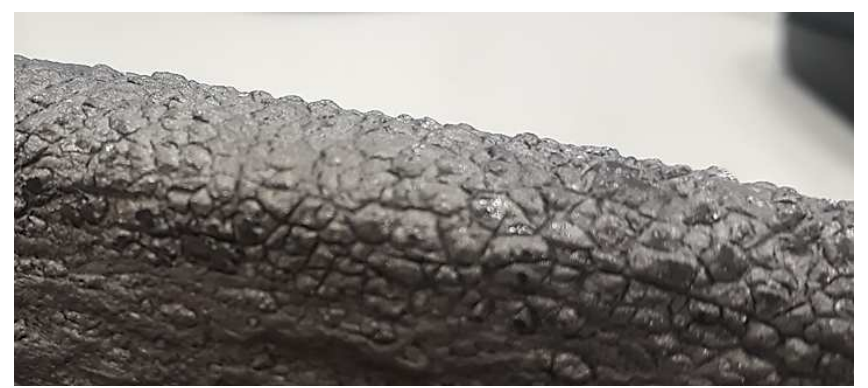

Fig. 8 Surface of a forged workpiece at the top of the wing.

The lathed parts were fixed to the mandrel clamping the outer circumferential surfaces and worked from both sides.

The process parameters, for each lathing and milling phase, are schematized in Table 2. For the parts obtained by only machining the starting raw material was a billet $70 \mathrm{~mm}$ in diameter and $14 \mathrm{~mm}$ in height for case 1 , and a square billet with $\mathrm{H}=154 \mathrm{~mm}, \mathrm{~L}=70 \mathrm{~mm}$ and $\mathrm{W}=45 \mathrm{~mm}$ for case 2

Table 2: the process parameters for the lathing and milling phases

\begin{tabular}{lccccc}
\hline \multirow{2}{*}{ Ti grade5 } & \multicolumn{2}{c}{$\begin{array}{c}\text { Casted and Forged Billets } \\
\text { (lathing phase) }\end{array}$} & \multicolumn{2}{c}{$\begin{array}{c}\text { Casted and Forged Billets } \\
\text { (milling phase) }\end{array}$} \\
\cline { 3 - 6 } & & Roughing & Finishing & Roughing & Finishing \\
\hline Spindle Speed & {$[R P M]$} & 763 & 916 & 694 & 810 \\
Feed Speed & {$[\mathrm{mm} / \mathrm{min}]$} & 0.20 & 0.15 & 195 & 162 \\
Depth of Cut & {$[\mathrm{mm}]$} & 2.5 & 0.5 & 4 & 0.5 \\
\hline
\end{tabular}

\subsubsection{Additive Manufacturing Processes}

Two different additive manufacturing processes were taken into account, i.e., Select Laser Melting and Electron Beam Melting. In the L-PBF process, specimens were produced using a Renishaw AM250 machine with the laser power set to $350 \mathrm{~W}$, hatch distance of $55 \mu \mathrm{m}$, layer thickness of $30 \mu \mathrm{m}$ and an Argon atmosphere with the gas recirculation at $25 \mathrm{~Hz}$. During the 
process, the build platform was maintained at $400^{\circ} \mathrm{C}$. The scanning was performed in stripes, assuming a rotation between two consecutive layers equal to $67^{\circ}$.

Regarding the E-PBF process, the specimens were produced using Arcam A2X machine with laser power of $5 \mathrm{~kW}$, Hatch distance of $55 \mu \mathrm{m}$ and a layer thickness of $90 \mu \mathrm{m}$. It is worth noting that the E-PBF process demands a high vacuum level. An interlock on the chamber pressure requires 1.6 x10-4 mBar in order to start the high voltage supply. The Electron Beam Unit requires $8.0 \times 10^{-7} \mathrm{mBar}$ or lower in order to guarantee the cathode lifetime. During the process, the build platform was maintained at $730^{\circ} \mathrm{C}$. The scanning strategy was a meander line technique.

For each test, the specimens were positioned in the machine as illustrated in Fig. 9.

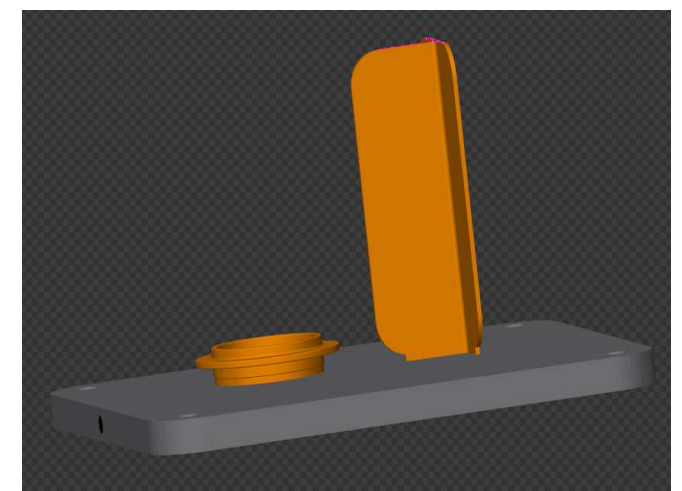

Fig. 9 Positioned specimens for the L-PBF and E-PBF experiments

\section{Results and discussion}

The parts were scanned, in order to test the geometrical accuracy, using a Steinbichler Comet $53 \mathrm{D}$ scanner and examined for possible distortions by comparing the scanned geometry to an ideal CAD model using the Geomagic Control X software.

Density measurements were carried out with forging and machining. The tests were carried out according to the ASTM B962-13 standard using a hydrostatic weighing scale.

The microstructure analysis of the produced parts was carried out through optical microscopy (mod. Zeiss Axioplan 2) and SEM (mod. Hitachi TM3000 with $15 \mathrm{kV}$ voltage). The samples were prepared following standard metallographic specimens preparation procedure and etching the surfaces with Keller's reagent. Regardless of the specific technology considered, the microstructure observation was performed along two orthogonal directions: in the case of the T elements, these are represented by the transverse and the longitudinal direction, while for the axisymmetric parts they are represented by the in-plane section and the radial section.

With the aim to evaluate the effects of the different processes on the final chemical composition of the produced parts, an Energy Dispersive X-ray Spectroscopy analysis (EDS) was carried out on the samples using an EDS module (mod. SWIFTED3000, Oxford Instruments) equipped with the SEM.

Vickers microhardness indentations were performed with the aim to provide a comparison between the mechanical properties of the produced parts. The tests were performed according to the ASTM E384-17 standard [ASTM], applying an indentation load of 500g for a dwell time of $15 \mathrm{~s}$.

Finally, surface roughness measurements were performed by means of confocal microscopy (mod. Leica DCM3D) in order to compare the typical finish of machining with the one of the as-processed additively produced ones.

\subsection{Geometrical accuracy}


The parts produced through the three different manufacturing routes are shown in Fig. 10.
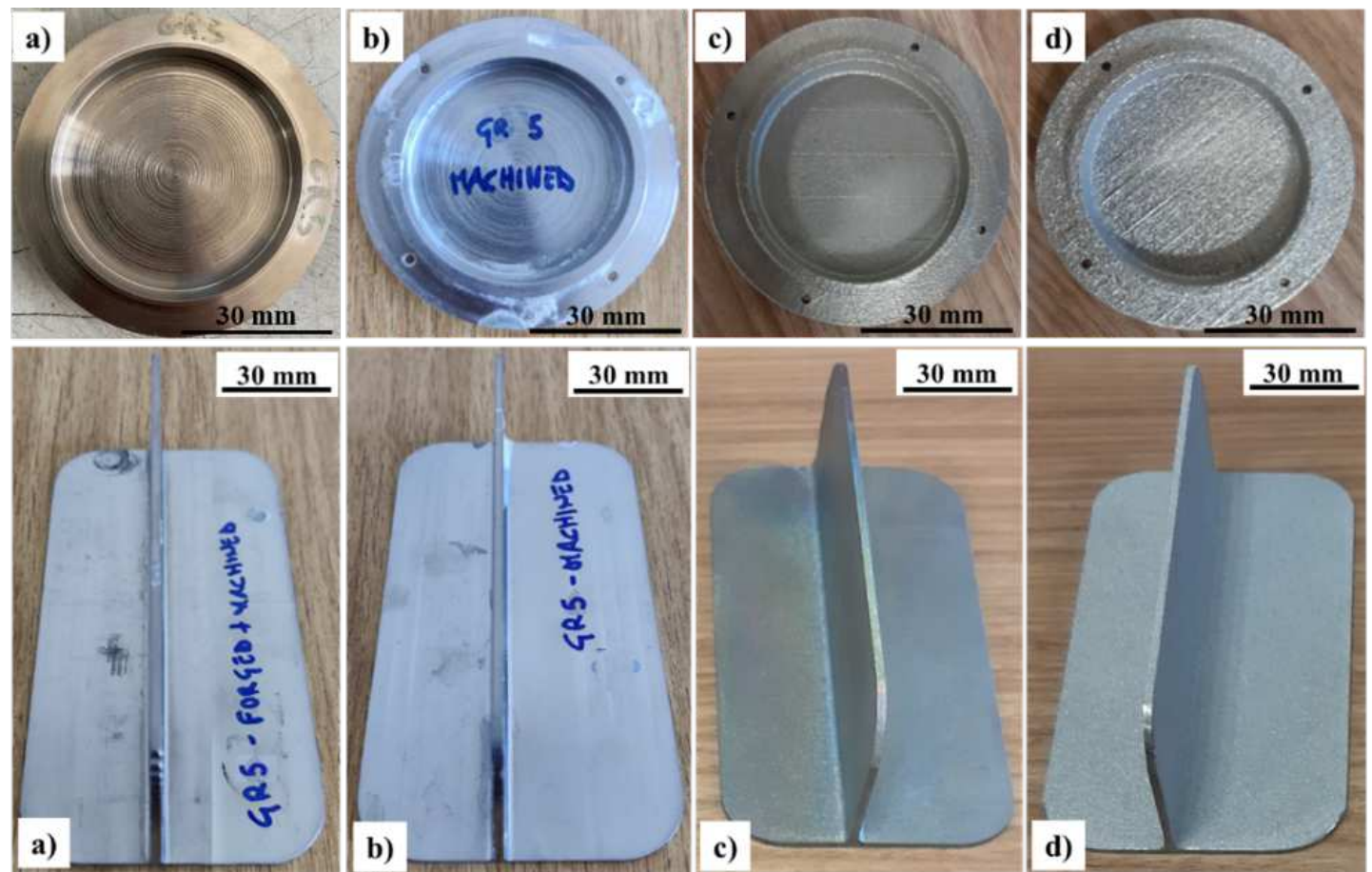

Fig. 10 Parts obtained through the four processes: a) Forged + Machined, b) Machined, c) L-PBFed and d) EPBFed

For the case study 1 no obvious geometrical flaws were observed. Fig. 11 reports the results on the geometrical accuracy for the case study 2 .

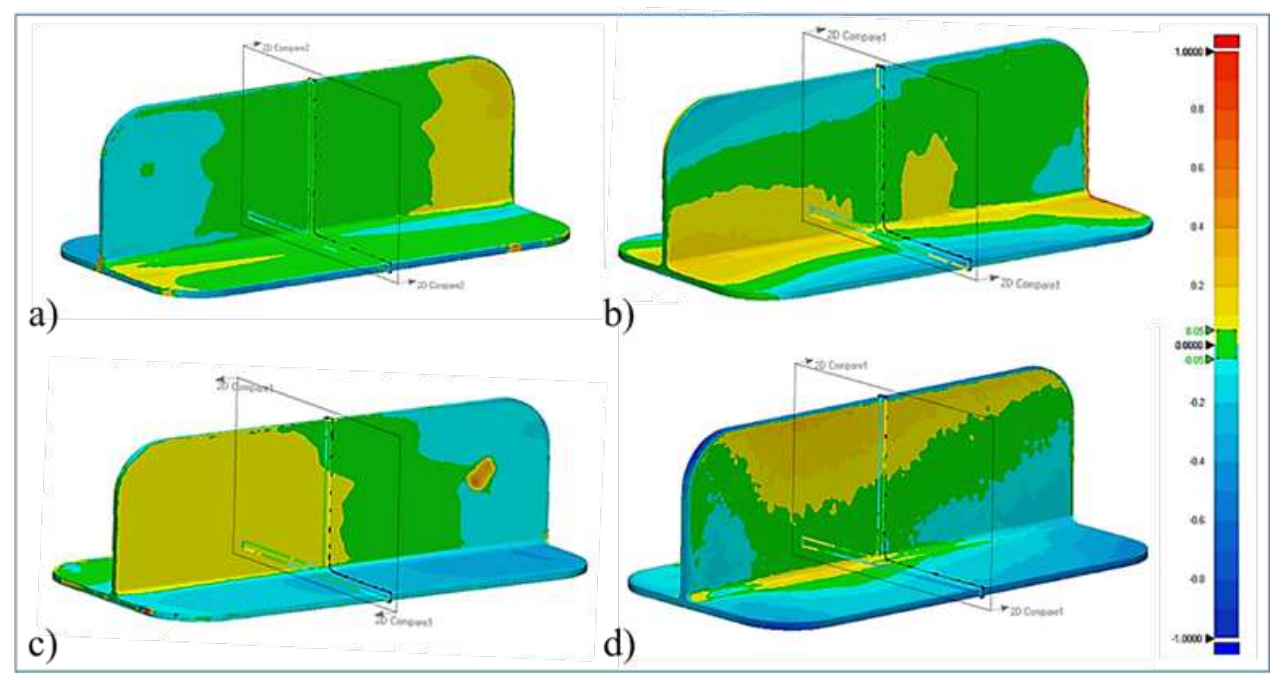

Fig. 11 Obtained parts using 3D scanner: a) Forged + Machined, b) Machined, c) L-PBF and d) E-PBF

Fig. 12 reports the transverse sections taken at mid-length of the parts as indicated in Fig. 11. It can be seen that the Forged + Machined (Fig. 12a) and the Machined (Fig. 12b) component were the best performing specimens of the four under analysis, with the machined component having the least geometric deviation. On the other hand, the worst performance was observed in the L-PBFed component, having a maximum deviation of about $1.30 \mathrm{~mm}$, located in the stringer (Fig. 12c). For the E-PBFed component, geometrical distortion was observed 
also in the skin; nevertheless, lower values of both maximum error and standard deviation were obtained with respect to the L-PBFed component.

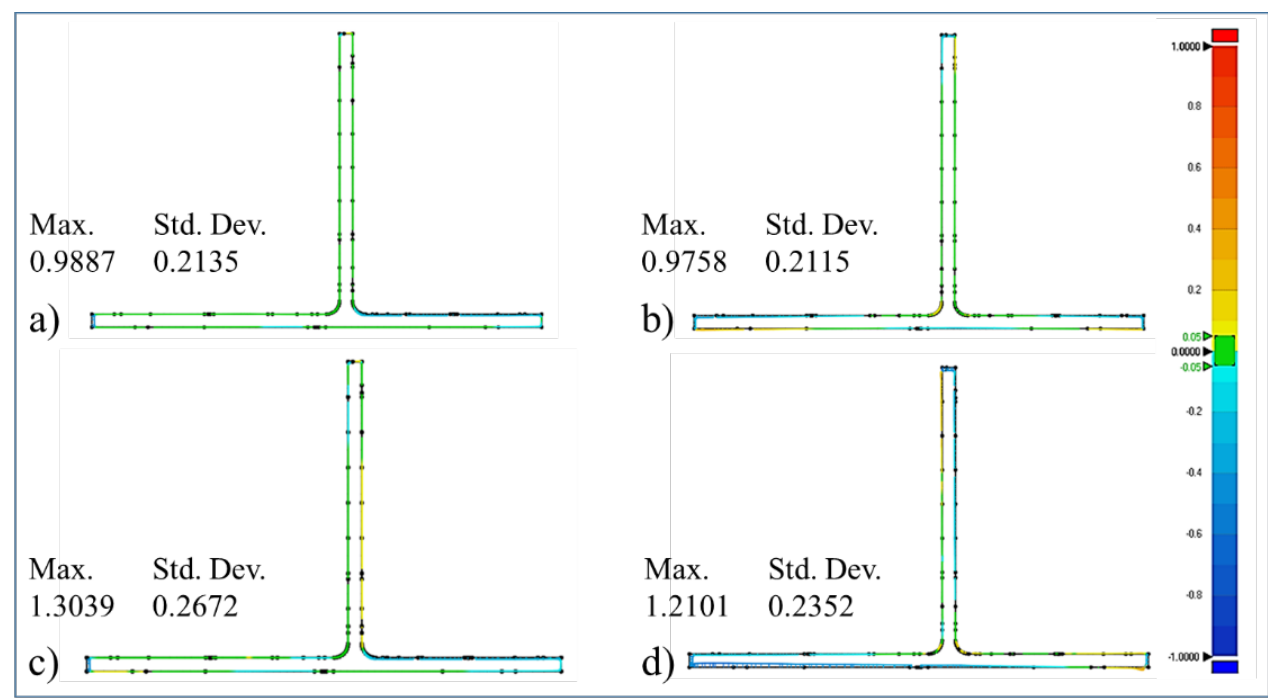

Fig. 12 Obtained parts using 3D scanner as processes: a) Forged + Machined, b) Machined, c) L-PBF and d) E$\mathrm{PBF}$

\subsection{Density}

Density measurements were carried out with the aim to compare the investigated additive manufacturing processes with the more traditional manufacturing routes. The results of the measurements are systematically reported in Fig. 13, sorted by the technology used and the parts geometry. As a general consideration, the results suggest that all the selected technologies lead to a density greater than $99 \%$, except for the case of E-PBF) whose values were lower especially for case study 2, i.e., the thin-walled T part. As expected, the parts produced by means of forging and machining were not affected by poor densification issues as they were obtained from the material removal of extruded bars with no appreciable inner defects. Concerning the L-PBF and E-PBF processes, it is worth to note that critical aspects related to the process variables and part geometry are highlighted in literature [21-25]. In particular, a few authors investigated the issues of producing thin-walled geometries through the leading PBF metal AM technologies, i.e., L-PBF and E-PBF, highlighting the effects of the fundamental process parameters such as heat source power, scanning speed and layer thickness on the overall build quality $[26,27]$. From the results, they reported that parts with thinner walls do suffer of a worse surface quality, lower static and dynamic mechanical properties and higher hardness. In this context, the results reported in Fig. 13 indicate that, especially for E-PBF, for which the powder size distribution is usually larger compared to L-PBF, process criticisms may occur when considering thin walls due to the emphasized melt pool instabilities, and not sufficient powder bed packing [28]. These considerations justify the results obtained for the EPBF parts, for which the density of the axisymmetric geometry part is less sensitive to variations than the $\mathrm{T}$ part. 


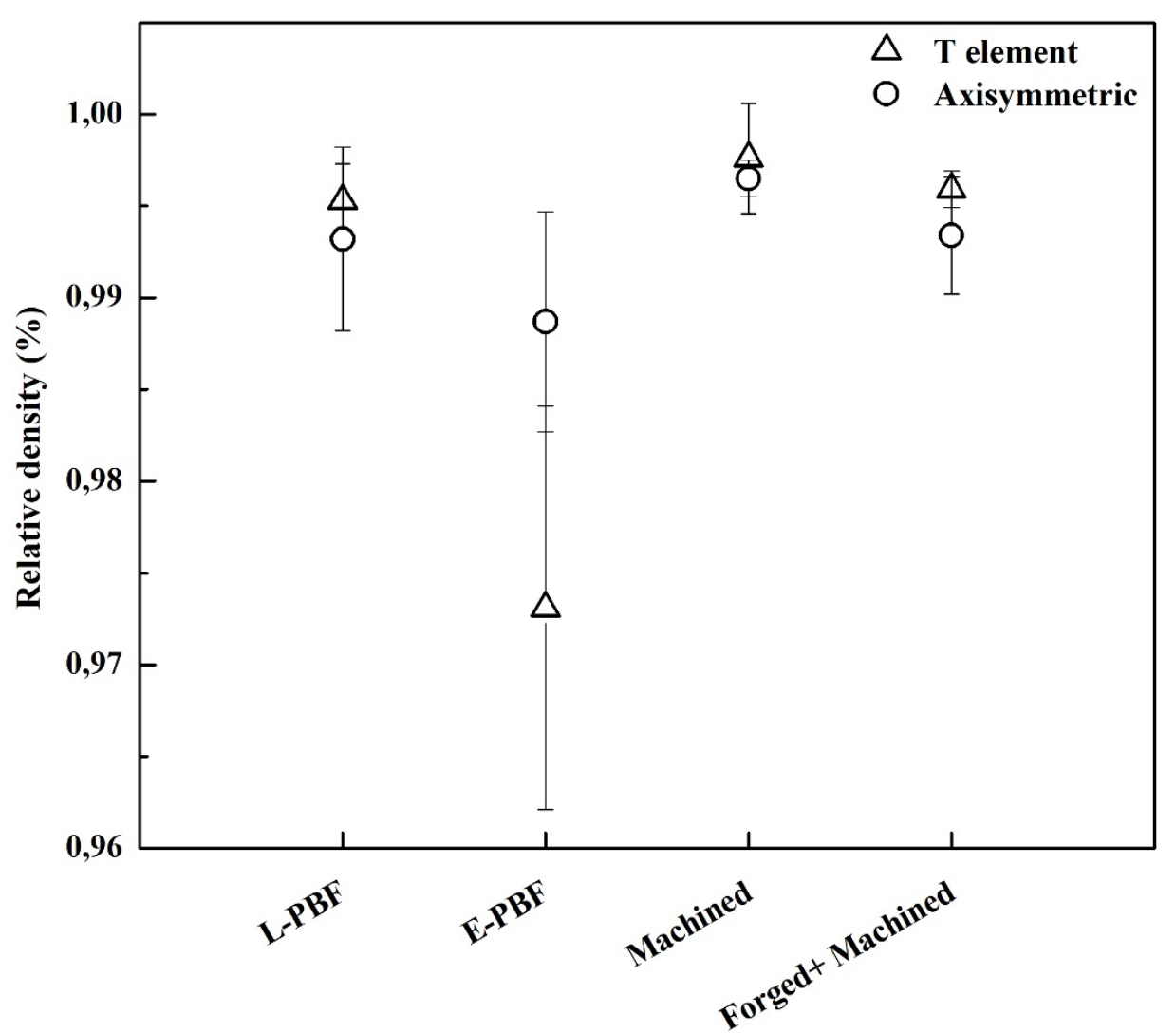

Fig. 13 Relative density comparison between the parts produced with different technologies and geometry (error bars indicate $\mathrm{a} \pm \sigma$ deviation).

\subsection{Microstructures}

In the following sub-paragraphs, the results of the microstructure analysis will be discussed according to the different processes used, the different geometry of the parts and the observation direction.

\subsubsection{Effects of the process used}

In Fig. 14 the optical macrographs that illustrate the microstructures comparison for the two selected geometries and the four selected technologies are reported. With the same rationale, in Fig. 15 the SEM micrographs are reported. From the obtained results, it can be observed that the different processes produced completely different microstructures, as expected. More specifically, a first comparison can be done between the AM processes and the more conventional processes, i.e., forging and machining. For the former, a very fine microstructure made of columnar grains can be observed because of the feedstock melting and subsequent solidification and cooling at very high rates [29]. Moreover, as reported in literature, both L-PBF and E-PBF produce very fine microstructures but with significant differences depending on the heat input entity, determined by the heat source characteristics, that induce different cooling rates [30]. For the case of L-PBF, the microstructure is mainly composed by $\alpha^{\prime}$ martensite needles that are overlapped along both the building direction and within a single layer. On the other hand, for the case of E-PBF, the process parameters used may induce a significant presence of martensite, like in the case reported in this work, or they may induce a basket-weave microstructure composed by the alternance of $\alpha$ and $\beta$ lamellae whose thickness is always larger than the $\alpha^{\prime}$ needles [30]. Moreover, for both L-PBF and E- 
PBF cases, the typical molten pools generated from these processes are not visible due to the aforementioned needles overlap. It is worth to note that, in any case, the lamellae formation takes place from the boundaries of the prior $\beta$ grains [31] and that the transition from $\beta$ to $\alpha$ phase during the material cooling always starts from the same boundaries, thus generating an $\alpha$ grain boundary layer [23]. The prior $\beta$ grains are also clearly visible in the microstructure of the parts produced by forging and machining, but not for the latter considered individually, for which the typical bi-modal microstructure can be observed. This result, as well known in literature, is dictated by the absence of material melting and, in the specific case of the forging process, by the intended processing in the $\beta$ field [32] according to the process parameters reported in the previous section. Therefore, as a general consideration, the forged and machined parts are characterized by a Widmanstatten microstructure for which $\alpha$ and $\beta$ lamellae are subsequent to the growth from the prior $\beta$ grains [33]. It is worth to note that the thickness of the lamellae is visibly higher for the forged and machined parts compared to the solely machined ones: this result, as expected, is subsequent to the material heating above the $\beta$ transus temperature for the forging process [34] and the slow cooling rate of the produced part. On the other hand, it can be seen from the microstructure of the forged and machined part that the original microstructure induced by the forging process was retained during the machining step, except for an appreciable grain growth that occurred.

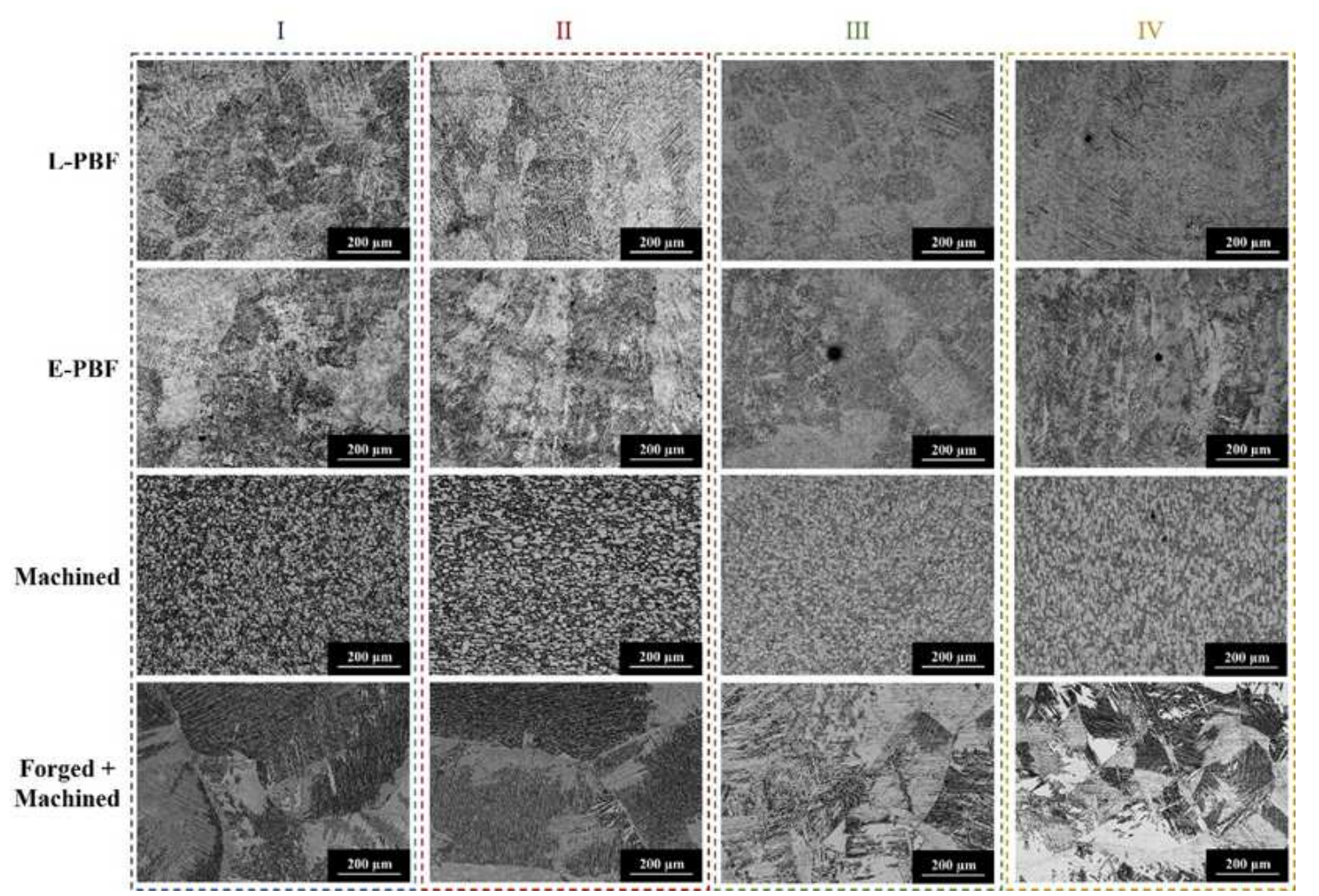

Fig. 14 Optical macrographs illustrating the microstructure comparison between the different parts and observation direction (100x magnification): I) T element, transverse section; II) T element, longitudinal section; III) Axisymmetric element, in-plane section; IV) Axisymmetric element, radial section. 
I

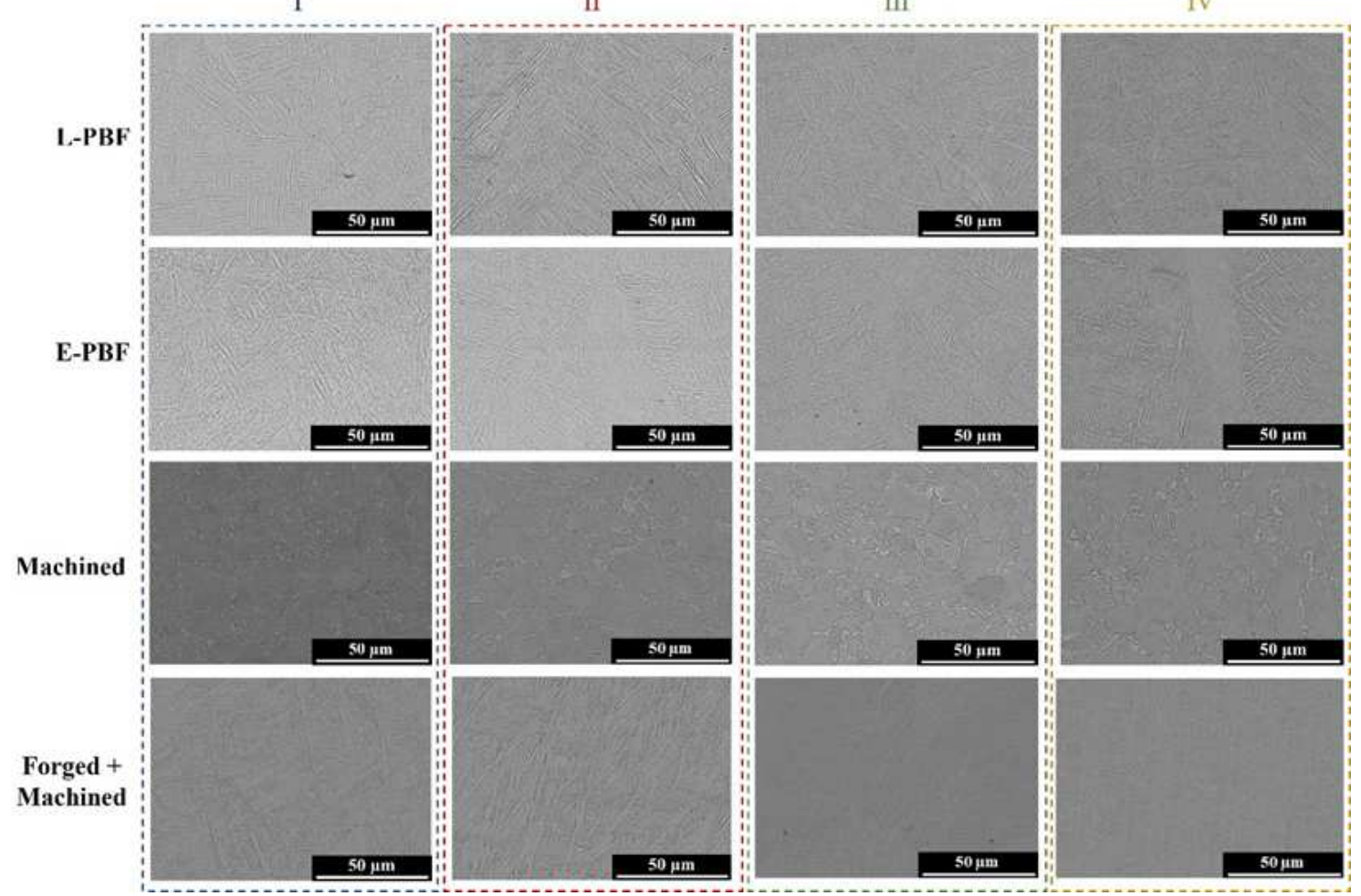

Fig. 15 High magnification SEM images representing the same microstructure comparison, but on a finer scale, between the different parts and observation direction (1500x magnification): I) T element, transverse section; II) T element, longitudinal section; III) Axisymmetric element, in-plane section; IV) Axisymmetric element, radial section.

\subsubsection{Effects of the part geometry and anisotropy}

To discuss the effects of the part design on the microstructure features and anisotropy for the different manufacturing processes, the optical macrographs and the SEM micrographs reported in Fig. 14 and Fig. 15 respectively can be compared by matching the columns I and III for the transverse and in-plane observation and by matching columns II and IV for the longitudinal and radial observation. From the comparison results, the following outcomes could be drawn: i) The microstructure of the L-PBF and E-PBF parts were not significantly affected by the specific part geometry: this result could be expected considering the principles of the two processes, for which the laser-matter interaction is almost independent from the intended geometry. As a matter of fact, part design features such as overhanging elements, high surface to volume ratio elements (e.g., lattice structures) and very thin walled elements are considered as source of parts properties heterogeneity, the latter intended in terms of microstructure, defects, hardness and so on [35-38]. On the other hand, despite this case study included a thinwalled structure, the overall mass of the part made it less sensitive to microstructure differentiation from the axisymmetric part.

ii) The microstructure of the parts produced by means of forging and machining, both individual and combined, presented an appreciable difference as a function of the considered part geometry: in the case of the forging step, the microstructure of a part is strictly dependent from the quantity of the material needed to perform the operation and the necessary strain path that the material experiences depending on the desired final shape. With this premise, it can be seen from Figs. 14 and 15 that the grain size of the $T$ element and the axisymmetric part is different. In the case of the machined parts, different conclusions could be drawn considering the absence of external heating for the desired formability increase. As clearly visible in Figs. 14 and 15, the original bi-modal microstructure of the extruded bar used as the feedstock (see 
Section 2.1.1) was preserved. Any microstructure differences should be demanded only to the material heating due to the machining process itself [12] and anisotropy.

iii) Every investigated part presented a significant microstructure anisotropy, as expected. Still based on the results reported in Figs. 14 and 15, this experimental outcome can be easily observed for each of the two selected geometries by matching the columns I-II and III-IV. Concerning the L-PBF and E-PBF technologies, the microstructure anisotropy is due to the preferential grains growth direction along the build direction. According to literature, the preferential growth direction of the grains during powder-based metal AM processes depends on the steepest thermal gradient that takes place during the molten pool formation and solidification. The latter is usually represented by the direction that goes from the molten pool boundaries towards the liquid free surface [39]. At the same time, the crystallites growth is also epitaxial, due to the presence of the building platform and the stacking of the layers during the build [39]. Therefore, in combination with the high cooling rates involved in L-PBF and EPBF, very fine and elongated grains can be observed along the building direction (columns IIIV) whereas quasi-equiaxed and coarser grains can be seen in the scan strategy plane (columns I-III). Concerning the forging step, the anisotropy is naturally expected considering in first the high strain involved, representing in this case the major source of anisotropy, as well as the microstructure anisotropy of the feedstock itself resulting from the extrusion process (see Section 2.1.1). The latter, on the other hand, can be considered as the primary source of anisotropy in the machined parts, but not when the combination of forging and machining is considered, for which the previous outcome of the forging step is still valid.

\subsection{Chemical composition}

The analysis was performed on the as-polished samples, using an SEM magnification of 500x. For the sake of brevity, only the analysis of the T-elements is reported. The obtained results, illustrated in Table 3 and Fig. 16 reporting the quantitative chemical composition and qualitative spectra respectively, showed that the chemical composition of the feedstock material was preserved (see Section 2.1.1). This result clearly suggests that, despite the different nature of the selected processes, the same alloy processed with these different technologies lead to comparable results. As a matter of fact, the preservation of the feedstock chemical composition is more delicate in the L-PBF and E-PBF processes, for which the melting of the powders could lead to the vaporization of the low melting temperature elements in the alloy [37]. However, if the process parameters are properly set, this issue can be mitigated, making L-PBF and E-PBF almost identical to the traditional manufacturing processes from this point of view.

Table 3 - Quantitative chemical composition of the produced T-elements evaluated through EDS analysis (values in the brackets indicate $\mathrm{a} \pm \sigma$ deviation).

\begin{tabular}{|c|c|c|c|}
\hline Element (wt \%) & $\mathrm{Ti}$ & $\mathrm{Al}$ & $\mathrm{V}$ \\
\hline $\mathrm{L}-\mathrm{PBF}$ & $90.2( \pm 0.18)$ & $6.11( \pm 0.08)$ & $3.71( \pm 0.17)$ \\
\hline E-PBF & $90.7( \pm 0.2)$ & $5.34( \pm 0.09)$ & $3.98( \pm 0.19)$ \\
\hline Machined & $89.7( \pm 0.29)$ & $6.11( \pm 0.13)$ & $4.15( \pm 0.27)$ \\
\hline Forged+Machined & $89.8( \pm 0.28)$ & $6.20( \pm 0.12)$ & $3.96( \pm 0.26)$ \\
\hline
\end{tabular}



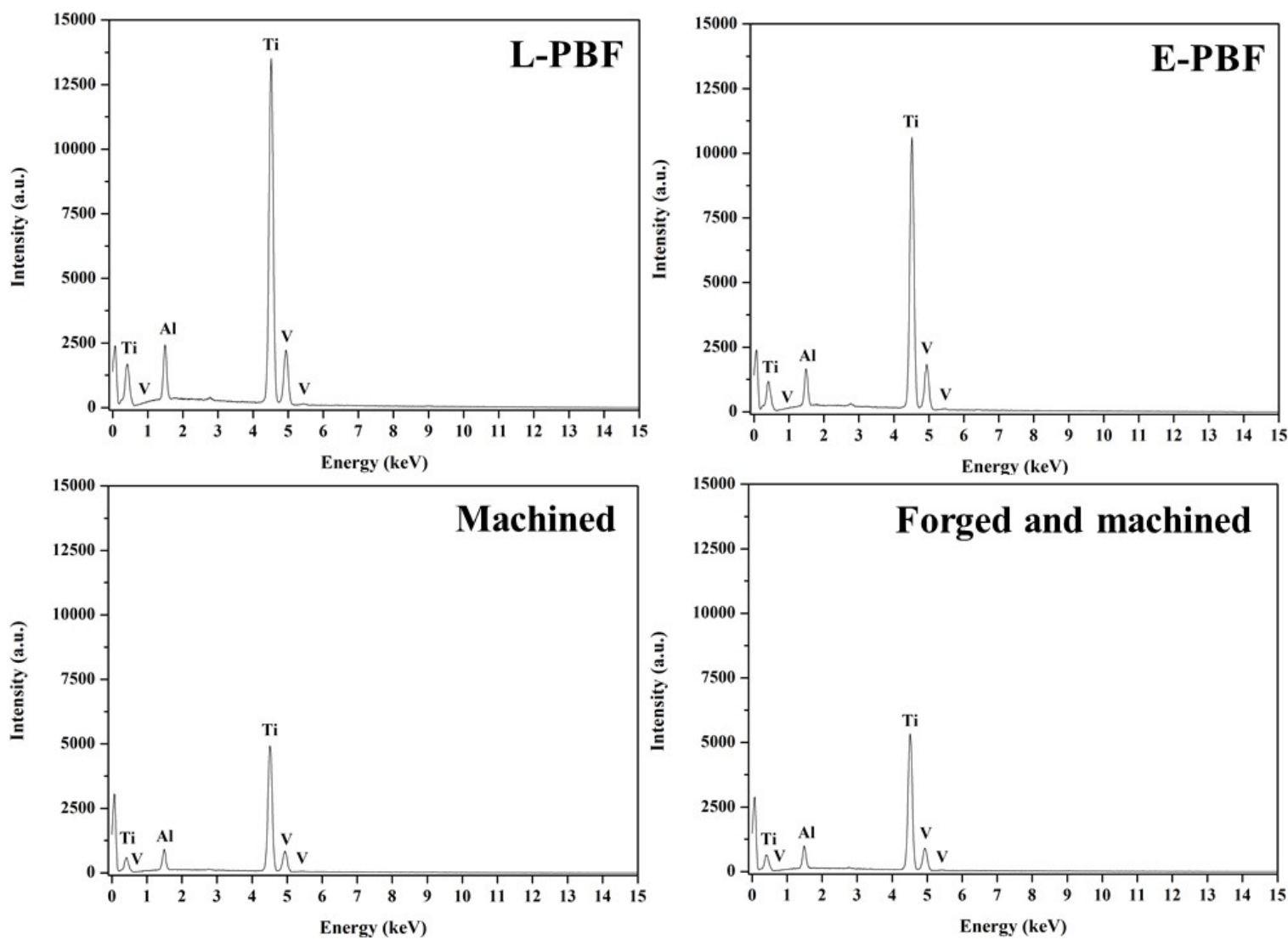

Fig. 16 EDS spectra of the T-elements produced with the investigated technologies.

\subsection{Microhardness}

The results are expressed as average and standard deviation considering a total of 15 indentations for each sample. Therefore, each datapoint reported in the Fig. 17 plot is the result of 10 indentations that incorporate the material anisotropy discussed in the previous section, as well as the different areas considered and illustrated in the Fig. 17 insets. It can be seen that the results are in agreement with the microstructure differences presented and discussed in the previous section, also according to the criterion proposed for focusing on the different aspects involved in this experimental campaign.

In first instance, the discussed differences between L-PBF and E-PBF results in terms of microstructure find support also in the microhardness results, showing a more stable behavior for the L-PBF process compared to E-PBF in relation to the part geometry. For the case of E$\mathrm{PBF}$, it is reasonable that a higher heat input would lead to a steeper cooling rate and thus to finer grains. According to the Hall-Petch law, this translates into higher hardness values [30], especially for a thin-walled part. However, another element of support is represented by the relative density plot shown in Fig. 13: given that the E-PBF parts presented a higher deviation in terms of density compared to the L-PBF counterparts, it is convincible that the presence of entrained defects such as porosities and lack of fusion would make less stable also the microhardness measurements in that case. Therefore, the microhardness results suggest again that the E-PBF technology, given the more intense and steep melting and cooling of the material, is more sensitive to formation of defects that could compromise the final properties of the parts. It is worth to note that the difference in terms of mechanical properties were highlighted in literature also as a function of the building direction, determining the anisotropy discussed in the previous section, as well as a function of the processing parameters $[24,30]$. 
The microstructure differences illustrated in Figs. 14 and 15 provide also support for the results obtained in the case of the machined parts, with and without the prior forging step. From Fig. 17 , it can be noted that the microhardness of the forged and machined parts presented an appreciable difference as a function of the part geometry: this result is in agreement with the fact that the T-element experienced a higher strain than the axisymmetric part during the process, leading therefore to a more consistent strain hardening. Moreover, the microhardness values agree with the fact that the microstructure of the forging step was almost entirely preserved after machining, given the higher microhardness values compared to the solely machined parts.

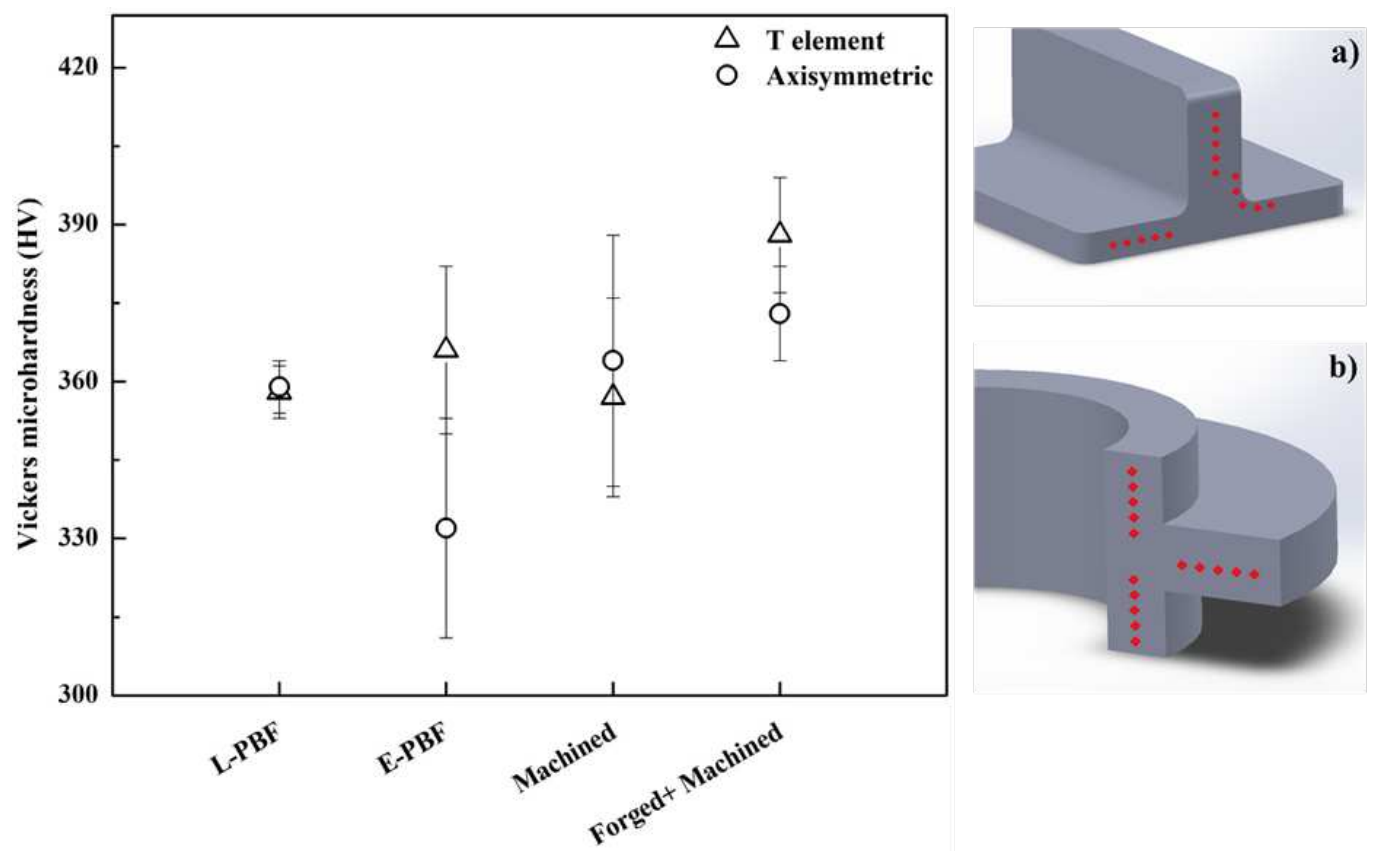

Fig. 17 Vickers microhardness comparison between the parts produced with different technologies and geometry (error bars indicate $\mathrm{a} \pm \sigma$ deviation). The insets $\mathrm{a}$ and $\mathrm{b}$ indicate the regions of indentation for the $\mathrm{T}$ element and the axisymmetric parts respectively.

\subsection{Surface Quality}

As a further element of comparison between the selected parts and processing routes, the surface quality was investigated. With this aim, surface roughness measurements were performed by means of confocal microscopy (mod. Leica DCM3D). The measurements were taken according to the regions of interest illustrated in Fig. 6: for the T-elements (Fig. 18a), three areas at the rear wall of the parts were used: the reason of this choice is dictated by the vertical build direction of the L-PBF and E-PBF parts, for which the homogeneity of the surface quality could be assumed given the absence of upskin and downskin surfaces that certainly introduce differences [41]. For the same reasons, three areas were chosen on the same side for the axisymmetric parts (Fig. 18b). For each of three areas, used for repeatability reasons, a square with a $5 \mathrm{~mm}$ side was considered and a 10x magnification and a focus range of $400 \mu \mathrm{m}$ were selected as the scan parameters.

Once the raw datapoints were acquired, the in-bundle software LeicaMap v7® was used to perform post-acquisition operations such as tilt correction, outliers removal and the extraction of the surface quality indicator. Concerning the latter, the areal mean arithmetic heights distribution $\left(\mathrm{S}_{\mathrm{a}}\right)$ was chosen according to ISO 25178 standard [ISO]. This choice was due to the greater robustness if compared to the most used profile equivalent $\mathrm{Ra}$ [ISO 4287], especially when metal AM parts are considered $[41,42]$. 


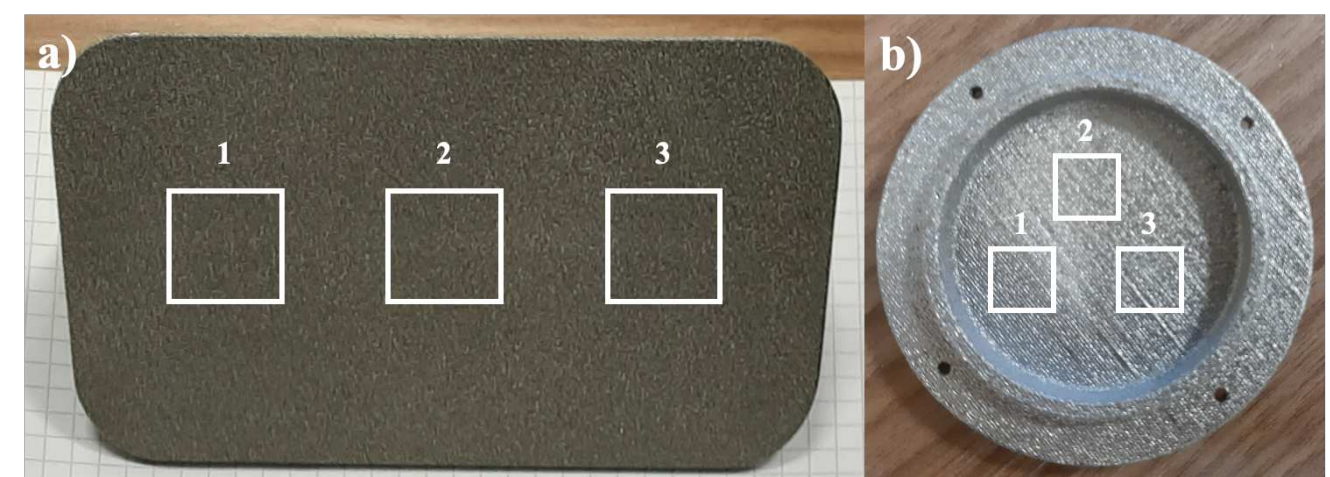

Fig. 18 Picture illustrating the selected areas for the confocal microscopy measurements: a) T-element; b) Axisymmetric element.

The results of the measurements, similarly to the previous sections, are reported in a plot that recalls the surface quality for the different parts geometry and processing technology, as illustrated in Fig. 19. As expected, the results revealed that the machining operation, both individual and combined with forging, led to the best surface quality in comparison with the $\mathrm{AM}$ processes as the values of Sa were of $2.7 \pm 1.2 \mu \mathrm{m}$ and $0.6 \pm 0.3$ respectively for both the considered geometries. The poor surface quality of the L-PBF and E-PBF parts can be explained, also according to literature, by the stair-step effect and balling phenomenon, leading to a surface texture characterized by curved features that are approximated by the stacking of the layers and a sintered powder-rich surface respectively $[43,44]$. Moreover, as already recalled in Section 3.3, among the AM technologies the worst case is represented by the Telement obtained through E-PBF, given the general issues of producing thin-walled parts and the larger feedstock size for the E-PBF process. Therefore, despite the specific powder-based metal AM technology, it is well known in literature that post-build surface finishing treatments are required to make the parts compliant with the desired final application.

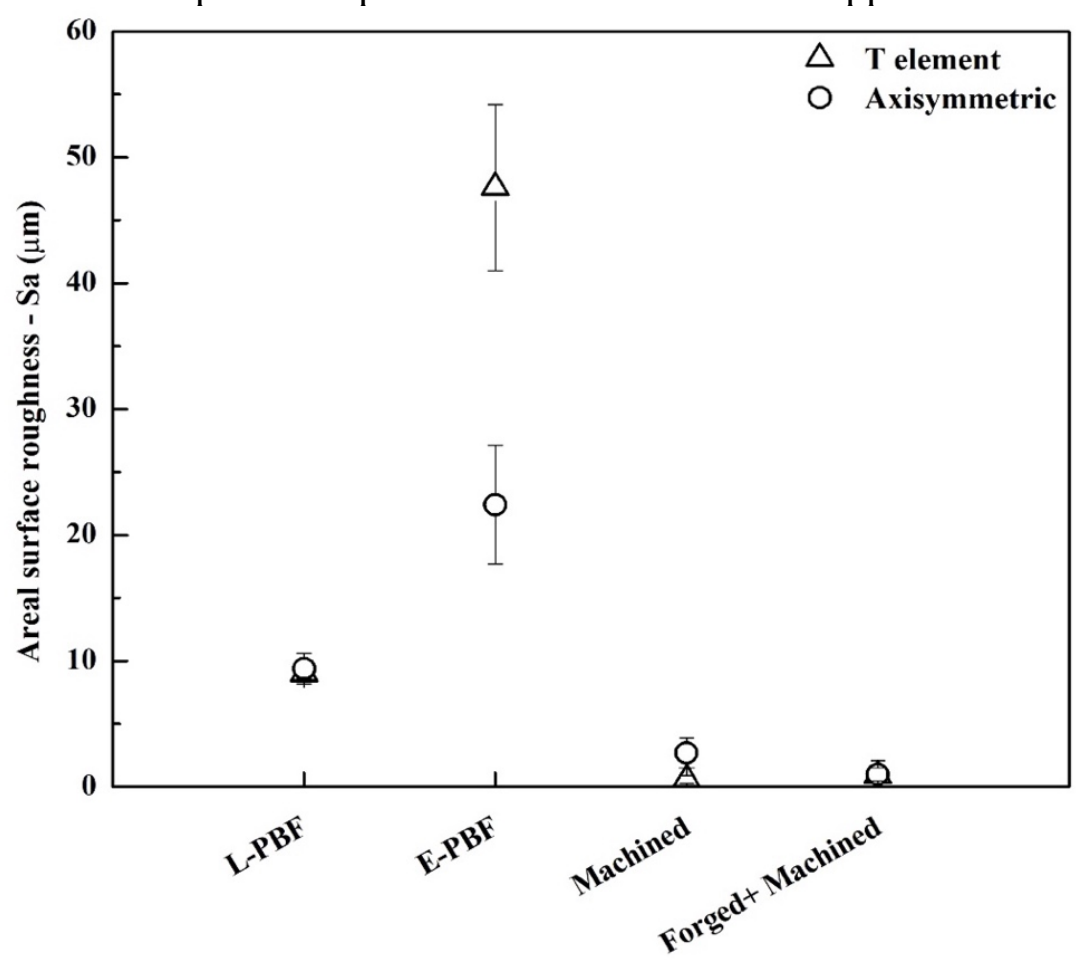

Fig. 19 Surface roughness (Sa) comparison between the parts produced with different technologies and geometry (error bars indicate a $\pm \sigma$ deviation). 


\section{Discussion}

From the results presented in the previous paragraph, it arises that the additive manufacturing technologies have lower performances when parts distortions, density, microhardness, and material finish are regarded. However, proper considerations have to be done. On the one hand, it is worth noting that, through proper process optimization, which was not the aim of this work, both distortion, density and microhardness distribution can improve for the additively manufactured components. On the other hand, martensite dominated microstructure and poor surface finishing are intrinsic characteristics of the above cited process and can hardly be modified by process parameters optimization procedures. The former, depends on the thermal flow occurring during the cool down of the parts after each layer processing, and can only partially modified by proper choice of process parameters as building direction and scan strategy. The latter is a direct consequence of the above cited thermal cycles. Hence, the possibility to customize and design the part microstructure is more limited in AM technologies with respect to forging, for which the choice of the process temperature result in very different microstructures of the final part. Additionally, for a more comprehensive comparison between the considered manufacturing processes, it can be observed that the buy-to-fly ratio, i.e. the ratio between the weight of the raw material and the one of the final component, is a key parameter especially for applications, as the one here considered, for which very expensive materials are used. Figure 20 shows the buy-to-fly ratio for the different processes and geometries considered in this study.

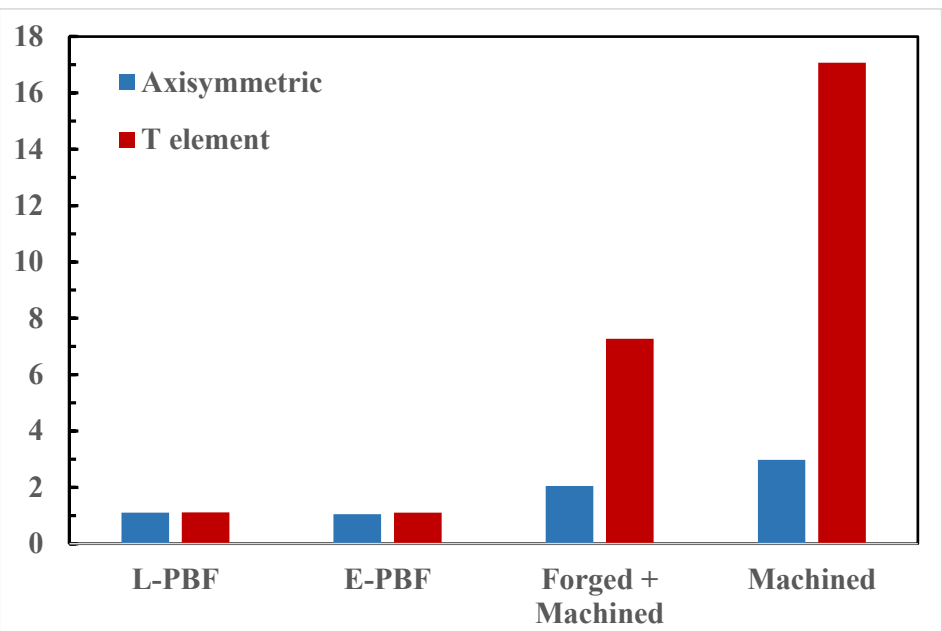

Fig. 20 Buy-to-Fly ratio for the parts produced with different technologies and geometry.

A dramatic difference is observed between the different case studies. For AM powder bed technologies, a large part of the unused powder can be reused, leading to buy-to-fly ratio values close to 1 [45]. As the axisymmetric part is concerned (case study 1), an increase in the buyto-fly ratio is observed as the used technology changes from AM to forging and finally machining, for which a value of about 3 is calculated. Although the same trend is observed for the T part (case study 2), the increase in the ratio when forging and machining are considered is dramatic, reaching values of about 7 and 17, respectively. In this way, it can be observed that the geometrical complexity of the part to be produced plays a key role in the determination of the buy-to-fly ratio. Besides the fact that the full potential of the AM technologies can be enabled only when dedicated parts design, not obtainable with conventional technologies, is pursued, from Fig. 20 it is visible that even a relatively simple geometry, like the one characterizing the case study 2 , can enable the peculiar advantages of these processes 


\section{Summary and conclusions}

In the paper, the results of an experimental campaign, aimed at the comparison of different manufacturing routes for the production of Ti6Al4V parts for aeronautical application, are presented. Two different geometries were considered, and the mechanical, geometrical, and microstructural characterization of the parts was carried out. From the obtained results the following main conclusions can be drawn:

- Geometrical features, as thin walls, have an impact on the parts distortion measured in the additively produced parts. The T component produced by L-PBF showed higher distortion in the stringer, with maximum value of about $1.3 \mathrm{~mm}$.

- As parts density is regarded, the E-PBF process is more sensitive to the presence of thin walls with respect to the L-PBF one. For the former process the lowest values, equal to about $97 \%$, were obtained.

- Significantly different microstructures can be obtained as a function of the considered manufacturing route. While for machining the microstructure of the part core is minimally affected by the process, the choice of process temperature in forging allows to determine the final microstructure (alpha dominated or lamellar alpha+beta). For AM processes, very fine microstructure made of columnar grains made, for both the considered processes, mainly of alpha-martensite, was observed.

- Anisotropy was observed for all the considered case studies: for the AM technologies, this depends on preferential grains growth direction along the chosen build direction; for the forging process it depends on the strain distribution peculiar of each geometry; for the machined parts, parts anisotropy depends solely on the anisotropy of the feedstock material.

- The different microstructure directly affects the micro-mechanical properties of the parts. Larger microhardness values were found for the machined parts, while larger variability was observed for the E-PBFed part, consistently with the lower density observed resulting in more defects and porosities.

- Surface finishing is relatively low for E-PBF parts, as expected, being surface roughness (Sa) higher for the $\mathrm{T}$ element due to the effect of the chosen process parameters as building orientation.

- Despite of the part geometry, the buy-to-fly ratio is minimal for the AM technologies and increases as the manufacturing route changes to forging and machining. The part geometry plays a key role for the buy-to-fly ratio as forged and machined components are regarded, reaching values as high as 7 and 17, respectively, for the thin-walled component.

\section{Acknowledgement}

This study was carried out using Italian MUR funds: "on the ChOice of Manufacturing Processes for Effective Titanium componEnts (COMPETE)”, PRIN 2017.

\section{Declarations}

- Ethical Approval the Authors Disclose potential conflicts of interest; also, the research here presented does not involve either Human Participants or Animals.

- Consent to Participate: Not Applicable

- Consent to Publish: Not Applicable

- Authors Contributions:

Davide Campanella: Performing experimental, analysis of the results and draft writing. 
Andrea El Hassanin and Francesco Gagliardi: Analysis of the results and draft writing.

Gianluca Buffa: Draft revision and research coordination.

Luigino Filice and Antonino Squillace: Research coordination.

Livan Fratini: Conceiving the idea, overall revision, and research coordination.

- Funding: Italian MUR funds

- Competing Interests: The Authors disclose any financial and non-financial competing interests that could inappropriately influence, or be perceived to influence, this work.

- Availability of data and materials: Not Applicable

\section{References}

[1] D. Banerjee, J.C. Williams, Perspectives on Titanium Science and Technology, Acta Materialia. (2013) 844-879. https://doi.org/https://doi.org/10.1016/j.actamat.2012.10.043.

[2] H. Attar, S. Ehtemam-Haghighi, D. Kent, M.S. Dargusch, Recent developments and opportunities in additive manufacturing of titanium-based matrix composites: A review, International Journal of Machine Tools and Manufacture. 133 (2018) 85-102. https://doi.org/https://doi.org/10.1016/j.ijmachtools.2018.06.003.

[3] B. Blakey-Milner, P. Gradl, G. Snedden, M. Brooks, J. Pitot, E. Lopez, M. Leary, F. Berto, A. du Plessis, Metal additive manufacturing in aerospace: A review, Materials \& Design. 209 (2021). https://doi.org/https://doi.org/10.1016/j.matdes.2021.110008.

[4] The Business Research Company, The Business Research Company, Aerospace Global Market Report 2021: COVID 19 Impact and Recovery to 2030, 2021.

[5] Z.M. Wang, E.O. Ezugwu, Performance of PVD-coated tools when machining Ti-6Al4V, Tribology Transactions. 40 (1997) 81-87.

[6] D.C. Kirk, Tools and dies for industry, in: Proceedings of Conference 76/77, 1976: pp. 77-78.

[7] E.O. Ezugwu, R.B. da Silva, J. Bonney, A.R. Machado, The Effect of Argon-Enriched Environment in High-Speed Machining of Titanium Alloy, Tribology Transactions. 48 (2005) 18-23.

[8] B. Wang, L. Cheng, D. Li, Experimental Study on Forged TC4 Titanium Alloy Fatigue Properties under Three-Point Bending and Life Prediction, Materials. 14 (2021). https://doi.org/https://doi.org/10.3390/ma14185329.

[9] A. Ducato, G. Buffa, L. Fratini, Dual phase titanium alloy hot forging process design: experiments and numerical modeling, Advances in Manufacturing. 3 (2015) 269-281. https://doi.org/https://doi.org/10.1007/s40436-015-0127-0.

[10] Z.M. Hu, T.A. Dean, Aspects of forging of titanium alloys and the production of blade forms, Journal of Materials Processing Technology. 111 (2001) 10-19. https://doi.org/https://doi.org/10.1016/S0924-0136(01)00510-6.

[11] Z.M. Hu, J.W. Brooks, T.A Dean, Experimental and theoretical analysis of deformation and microstructural evolution in the hot-die forging of titanium alloy aerofoil sections, Journal of Materials Processing Technology. 88 (1999) 251-265. https://doi.org/https://doi.org/10.1016/S0924-0136(98)00407-5.

[12] W.E. Frazier, Metal Additive Manufacturing: A Review, Journal of Materials Engineering and Performance. 23 (2014) 1917-1928. https://doi.org/10.1007/s11665-014-0958-z. 
[13] V.K. Singoria, Samsher, Mechanism, Characterization, Pattern and Effect of Roughness over Turbine Blade: A Review, International Journal of Engineering and Innovative Technology. 2 (2013).

[14] B. Dutta, F.H. (Sam) Froes, The Additive Manufacturing (AM) of titanium alloys, Metal Powder Report. 72 (2017) 96-106. https://doi.org/10.1016/j.mprp.2016.12.062.

[15] N. Nazemzadeh, A.A. Soufivand, N. Abolfathi, Computing the bond strength of 3D printed polylactic acid scaffolds in mode I and II using experimental tests, finite element method and cohesive zone modeling, International Journal of Advanced Manufacturing Technology. 118 (2022) 2651-2667. https://doi.org/10.1007/S00170021-08124-W/FIGURES/10.

[16] M.E. Ramosoeu, H.K. Chikwanda, A.S. Bolokang, G. Booysen, T.N. Ngonda, Additive manufacturing: Characterization of TI-6Al-4V alloy intended for biomedical application, (n.d.). http://hdl.handle.net/10204/4617.

[17] O. Yilmaz, A.A. Ugla, Shaped metal deposition technique in additive manufacturing: A review, Proceedings of the Institution of Mechanical Engineers, Part B: Journal of Engineering Manufacture. 230 (2016) 1781-1798. https://doi.org/10.1177/0954405416640181.

[18] R. Boyer, G. Welsch, E.W. Collings, Ti-8Mn, Materials Properties Handbook - Titanium Alloys. (1994) 755-763.

[19] I.J. Polmear, Light alloys : metallurgy of the light metals, 2nd ed., Edward Arnold, London [etc], 1989.

[20] S. Bruschi, S. Poggio, F. Quadrini, M.E. Tata, Workability of Ti-6Al-4V alloy at high temperatures and strain rates, Materials Letters. 58 (2004) 3622-3629. https://doi.org/10.1016/J.MATLET.2004.06.058.

[21] M. Bayat, S. Mohanty, J.H. Hattel, A systematic investigation of the effects of process parameters on heat and fluid flow and metallurgical conditions during laser-based powder bed fusion of Ti6Al4V alloy, International Journal of Heat and Mass Transfer. 139 (2019) 213-230. https://doi.org/10.1016/j.ijheatmasstransfer.2019.05.017.

[22] M. Bayat, A. Thanki, S. Mohanty, A. Witvrouw, S. Yang, J. Thorborg, N.S. Tiedje, J.H. Hattel, Keyhole-induced porosities in Laser-based Powder Bed Fusion (L-PBF) of Ti6Al4V: High-fidelity modelling and experimental validation, Additive Manufacturing. 30 (2019) 100835. https://doi.org/10.1016/j.addma.2019.100835.

[23] U. Prisco, A. Astarita, A. el Hassanin, S. Franchitti, Influence of processing parameters on microstructure and roughness of electron beam melted Ti-6Al-4V titanium alloy, Materials and Manufacturing Processes. 34 (2019) 1753-1760. https://doi.org/10.1080/10426914.2019.1683576.

[24] A.T. Silvestri, S. Foglia, R. Borrelli, S. Franchitti, C. Pirozzi, A. Astarita, Electron beam melting of Ti6Al4V: Role of the process parameters under the same energy density, Journal of Manufacturing Processes. 60 (2020) 162-179. https://doi.org/10.1016/j.jmapro.2020.10.065.

[25] J.Y. Huang, C.H. Chang, W.C. Wang, M.J. Chou, C.C. Tseng, P.W. Tu, Systematic evaluation of selective fusion additive manufacturing based on thermal energy source applied in processing of titanium alloy specimens for medical applications, International Journal of Advanced Manufacturing Technology. 109 (2020) 2421-2429. https://doi.org/10.1007/S00170-020-05797-7.

[26] Z.Y. Chua, S.K. Moon, L. Jiao, I.H. Ahn, Geometric influence of the laser-based powder bed fusion process in Ti6AL4V and AISi10Mg, International Journal of Advanced 
Manufacturing Technology. 114 (2021) 3165-3176. https://doi.org/10.1007/s00170021-07089-0.

[27] S.M.J. Razavi, B. van Hooreweder, F. Berto, Effect of build thickness and geometry on quasi-static and fatigue behavior of Ti-6Al-4V produced by Electron Beam Melting, Additive Manufacturing. 36 (2020) 101426. https://doi.org/10.1016/j.addma.2020.101426.

[28] V. Lampitella, M. Trofa, A. Astarita, G. D’Avino, Discrete Element Method Analysis of the Spreading Mechanism and Its Influence on Powder Bed Characteristics in Additive Manufacturing, Micromachines. 12 (2021). https://doi.org/10.3390/mi12040392.

[29] P.A. Hooper, Melt pool temperature and cooling rates in laser powder bed fusion, Additive Manufacturing. 22 (2018) 548-559. https://doi.org/10.1016/j.addma.2018.05.032.

[30] X. Zhao, S. Li, M. Zhang, Y. Liu, T.B. Sercombe, S. Wang, Y. Hao, R. Yang, L.E. Murr, Comparison of the microstructures and mechanical properties of Ti-6Al-4V fabricated by selective laser melting and electron beam melting, Materials and Design. 95 (2016) 21-31. https://doi.org/10.1016/j.matdes.2015.12.135.

[31] B. Tang, H. Kou, X. Zhang, P. Gao, J. Li, Study on the formation mechanism of $\alpha$ lamellae in a near $\beta$ titanium alloy, Progress in Natural Science: Materials International. 26 (2016) 385-390. https://doi.org/10.1016/J.PNSC.2016.06.009.

[32] S.R. Soundararajan, J. Vishnu, G. Manivasagam, N.R. Muktinutalapati, Processing of Beta Titanium Alloys for Aerospace and Biomedical Applications, Titanium Alloys Novel Aspects of Their Processing [Working Title]. (2018). https://doi.org/10.5772/INTECHOPEN.81899.

[33] S. Liu, Y.C. Shin, Additive manufacturing of Ti6Al4V alloy: A review, Materials \& Design. 164 (2019) 107552. https://doi.org/10.1016/J.MATDES.2018.107552.

[34] M. Motyka, Martensite Formation and Decomposition during Traditional and AM Processing of Two-Phase Titanium Alloys-An Overview, Metals 2021, Vol. 11, Page 481. 11 (2021) 481. https://doi.org/10.3390/MET11030481.

[35] F. Calignano, Design optimization of supports for overhanging structures in aluminum and titanium alloys by selective laser melting, Materials and Design. 64 (2014) 203213. https://doi.org/10.1016/j.matdes.2014.07.043.

[36] S. Ghaoui, Y. Ledoux, F. Vignat, M. Museau, T.H. Vo, F. Villeneuve, A. Ballu, Analysis of geometrical defects in overhang fabrications in electron beam melting based on thermomechanical simulations and experimental validations, Additive Manufacturing. 36 (2020). https://doi.org/10.1016/j.addma.2020.101557.

[37] S. Murchio, M. Dallago, F. Zanini, S. Carmignato, G. Zappini, F. Berto, D. Maniglio, M. Benedetti, Additively manufactured Ti-6Al-4V thin struts via laser powder bed fusion: Effect of building orientation on geometrical accuracy and mechanical properties, Journal of the Mechanical Behavior of Biomedical Materials. 119 (2021) 104495. https://doi.org/10.1016/j.jmbbm.2021.104495.

[38] R. Sepe, S. Franchitti, R. Borrelli, F. di Caprio, E. Armentani, F. Caputo, Correlation between real geometry and tensile mechanical behaviour for Ti6Al4V electron beam melted thin specimens, Theoretical and Applied Fracture Mechanics. 107 (2020) 102519. https://doi.org/10.1016/j.tafmec.2020.102519.

[39] A. Basak, S. Das, Epitaxy and Microstructure Evolution in Metal Additive Manufacturing, Annual Review of Materials Research. 46 (2016) 125-149. https://doi.org/10.1146/annurev-matsci-070115-031728. 
[40] D. Wang, Z. Liu, W. Liu, Experimental Measurement of Vacuum Evaporation of Aluminum in Ti-Al, V-Al, Ti6Al4V Alloys by Electron Beam, Metals. 11 (2021) 1688. https://doi.org/10.3390/met11111688.

[41] F. Cabanettes, A. Joubert, G. Chardon, V. Dumas, J. Rech, C. Grosjean, Z. Dimkovski, Topography of as built surfaces generated in metal additive manufacturing: A multi scale analysis from form to roughness, Precision Engineering. 52 (2018) 249-265. https://doi.org/10.1016/j.precisioneng.2018.01.002.

[42] C.A. Brown, H.N. Hansen, X.J. Jiang, F. Blateyron, J. Berglund, N. Senin, T. Bartkowiak, B. Dixon, G. le Goïc, Y. Quinsat, W.J. Stemp, M.K. Thompson, P.S. Ungar, E.H. Zahouani, Multiscale analyses and characterizations of surface topographies, CIRP Annals. 67 (2018) 839-862. https://doi.org/10.1016/j.cirp.2018.06.001.

[43] G. Strano, L. Hao, R.M. Everson, K.E. Evans, Surface roughness analysis, modelling and prediction in selective laser melting, Journal of Materials Processing Technology. 213 (2013) 589-597. https://doi.org/10.1016/j.jmatprotec.2012.11.011.

[44] T. DebRoy, H.L. Wei, J.S. Zuback, T. Mukherjee, J.W. Elmer, J.O. Milewski, A.M. Beese, A. Wilson-Heid, A. De, W. Zhang, Additive manufacturing of metallic components Process, structure and properties, Progress in Materials Science. 92 (2018) 112-224. https://doi.org/10.1016/j.pmatsci.2017.10.001.

[45] J. Liao, D.R. Cooper, The environmental impacts of metal powder bed additive manufacturing, Journal of Manufacturing Science and Engineering, Transactions of the ASME. 143 (2021). https://doi.org/10.1115/1.4048435/1086988. 